\title{
The Impact of Workplace Stress Management in a Business Organisation in the Service Industries - A Case Study on Kingstel Hotel Limited -Takoradi, Ghana
} Alex Acquah ${ }^{1}$, Prof. Huiying Chen ${ }^{2}$

1PG Scholar, Master of Business Administration, Liaoning University, Shenyang, China ${ }^{2}$ Professor, Master of Business Administration, Liaoning University, Shenyang, China

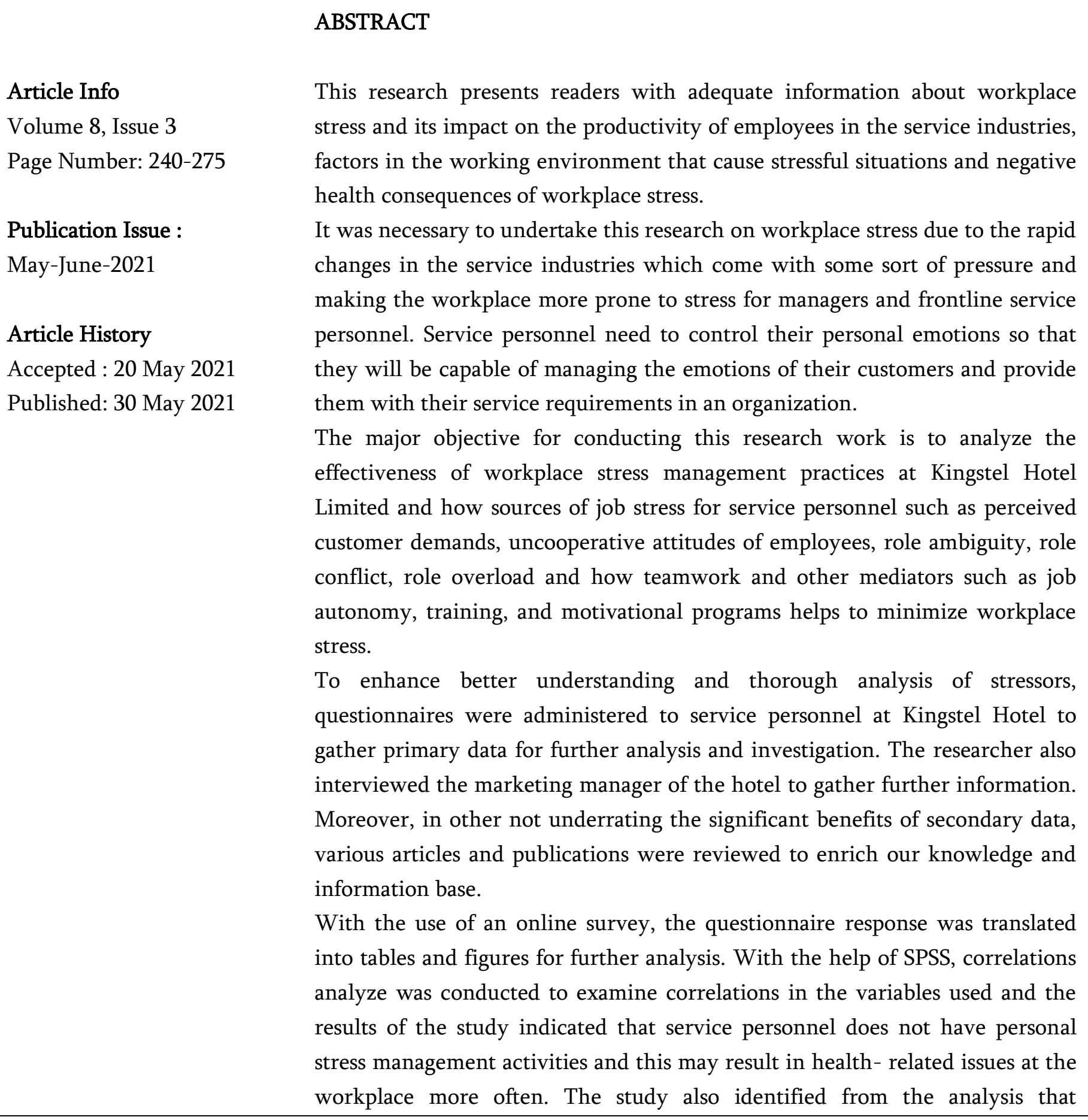

Copyright: (C) the author(s), publisher and licensee Technoscience Academy. This is an open-access article distributed under the terms of the Creative Commons Attribution Non-Commercial License, which permits unrestricted non-commercial use, distribution, and reproduction in any medium, provided the original work is properly cited 
workplace stress management activities will reduce working hours.

Findings suggest the more uncooperative colleagues tend to be in an organization, the heavier workload will be for employees and hence higher probability to suffer from stress. Finally, recommendations for future research are given and areas are highlighted where there is a need for more empirical research.

Keywords : Workplace Stress Management, Teamwork, Stress Management Practices, Service

\section{INTRODUCTION}

Countless people in today's society complain of "stress". The word is often misused, and used, in the most varied of meanings. What, then, do we mean by stress? How does it feel? What takes place in the body? Does it make sense to talk about stress illnesses? How common are they? Can stress be measured? Can stress be cured or, indeed, can it be prevented? It upon these numerous questions that's why the research on the stress management was conducted to find out why and how it affects employee's health, productivity and human resource and also suggest the best ways of managing it in a business organization.

In this time of economic crises, high competition, continuous broadcastings of negative news from around the world and appearance of new incurable and fast-spreading illness, people run the risk of having stress more and more frequently. "Stress nowadays is not something new, not anything unknown" (Agrawal, 2011).

The twenty-first-century work environment is experiencing dramatic changes all over the world due, in part, to rapid expansion in the service sectors, the emergence of new firms and competitions coupled with rapid technological advancement. In Ghana, the services sector contributed $51 \%$ of the GDP and employed $40 \%$ of the working population in the year 2015. These figures indicate the growth and performance of service industries in the country which is very essential for economic growth and development. Also, between 2005 and 2006, the share of services in GDP rose from $31 \%$ to $47.5 \%$ (www.economiesafricaines.com)

In the United States, service organizations are becoming a dominant force in creating new jobs. The U.S. Department of Labor reported rapid growth in the service industry from 1991 to 2000. Serviceoriented employment opportunities are projected to rapidly expand increasing in size by 5.1 million between 2000 and 2010 with over half of those jobs within the health, business, and social services industries (Hecker, 2001). With this rapid growth, there is a renewed interest among researchers in focusing on the critical issues underlying customers' perceptions of service providers, such as service encounter performance (Chenet, Tynan, \& Money, 1999).

These rapid changes in the service industries come with some sort of pressure and making the workplace more prone to stress for managers and frontline service personnel. For instance, lower-level managers perform many stressful functions amongst which include managing the stress of associates, counseling, understanding, motivating and identifying less significant jobs for layoffs. The performance of associates directly reflects on the efficiency of lowerlevel management meaning they always have to deal with the shortfalls of a lot of people. 
Frontline personnel perform duties such as answering the phone or helping clients in person in spaces like hotels, banks, and hospitals. Because they are the first point of call for many clients, they always need to exhibit a strong knowledge and skills on user experience and influence the public's perception of the brand they represent.

These valuable staff members need strong social and communication skills and are often trained to handle emergencies or taught how to calm upset clients. A friendly and convincing personality combined with appropriate training often leads to their success at work and better client satisfaction. This is necessary because, the service delivery encounter plays an important role in the development of the customer's impression of the service provider (McAlexander, Kaldenberg, \& Koening, 1994). A product can be described precisely (Shostack, 1977). However, service images and service realities are based largely

on our five senses (i.e., tangible things), but the service itself cannot be tangible. Thus, customers rely on peripheral clues (Shostack, 1977).

Some researchers suggest that frontline service personnel are the pulse of the service organization and the organization's image is often portrayed by the actions of just one frontline service personnel (Folkes \& Patrick, 2003). Other researchers note that customer satisfaction and actual purchase behavior are two important outcomes derived from the service encounter and are a function of the customer's service quality perceptions (Athanassopoulos, 2000; Chenet et al., 1999; Sweeney, Soutar, \& Johnson, 1999).

It is therefore obvious that the attitude of frontline service personnel contributes massively to the growth and success of the organization. Managers in an attempt to control and manage the desired consistency of service quality and maintain a high image of their organizations tend to implement specific strategies that impose emotionally-based behavior display rules on their frontline service personnel during the service delivery encounter.
While in some situations imposed emotionally-based behavior display rules are beneficial to frontline service personnel, these types of rules can also result in emotional labor, a potential source of increased social service encounter stress that negatively affects service encounter performances (Singh, 1998).

Almost all literature available on stress tends to emphasize employees' stress conditions. However, researchers fail to recognize the many stressors' managers and frontline service personnel are faced with. The study will focus mainly on the marketing manager and the entire frontlines service personnel in one of the most competitive businesses in the world, we chose the management and staff of Kingstel Hotel because we believe to maintain their lead in the hotel management industry in Ghana, the marketing manager, and his team, as well as the frontline service personnel of the hotel, should perform beyond ordinary standards due to the nature of work. Hotel management is one of the sectors in the service sector which deals directly with customers in their daily activities. Therefore, the stress associated with is high since it requires an extraordinary performance from management

and staff. This paper seeks to unravel the stress involved in this business and suggest effective ways of managing them.

\subsection{Background of the study}

It is clear from numerous researches works that job stress continues to be a major concern when it comes to the performance of employees in the service sector. That is because job performance is empirically linked to job stress (Singh, Goolsby, \& Rhoads, 1994). Job performance in the service sector is directly correlated with service quality (Chenet et al., 1999). This is because the fundamental truth is that customers perceive the quality of service, they receive from how they are treated by service personnel. For that reason, the actual service delivery is considered the moment of truth (Carlzon, 1987; Normann, 1983). 
It is at this point that the customer formulates the perception of quality, satisfaction, and long-term loyalty.

Unlike the commercial service sector where the product offering is a good or service, social marketers in social service organizations primary offering is a behavior change (Andreasen, 1995). Because of this uniqueness, quality is very difficult for the customer to assess. In many social service encounters, customers are expected to voluntarily accept, reject, modify, or abandon a behavior for their benefit, the benefit of a group, or of society without a promise of a direct benefit or immediate payback in return for their behavior change (Kotler, Roberto, \& Lee, 2002).

\subsection{Research Objectives}

One of the research objectives for this research work is to analyze the impact of workplace stress on the health and performance of employees at Kingstel hotel.

Besides, I also clarify the mechanisms and drivers which businesses in the service industry and management of business organization have in place to manage workplace stress. Due to inconsistencies in the literature, this paper reviews the impact of stressors such as role ambiguity (RA), role conflict $(\mathrm{RC})$, resource inadequacy (RI), and role overload (RO) monitoring (M), and Job insecurity (JI) from existing articles and publications. Again, the researcher researched from existing articles and publications to find out how some mediating factors such as job autonomy (JA), emotion-focused coping $(\mathrm{EFC})$, and emotional intelligence (EI) helps to reduce workplace stress.

The researcher also resorts to empirically examine and analyze the effectiveness of organizational and personal stress management practices of service personnel at Kingstel Hotel, and further find out how lack of stress management activities at the workplace affects the health of the service personnel.
Another objective is to find out as to what extent does the attitude of uncooperative employees affects the workload of employees in an organization.

Propose managerial strategies to Kingstel Hotel Limited for the management of workplace stress with the view of reducing workplace stress and its associated health issues thereby creating a stress-free working environment for management and staff of the company and personnel who occupy managerial positions.

\subsubsection{Definition of Terminologies}

To enhance a better understanding of this research work various definitions have been given as support.

Stress Defined "Job stress can be defined as the harmful physical and emotional responses that occur when the requirements of the job do not match the capabilities, resources, or needs of the worker. Job stress can lead to poor health and even injury." (United States National Institute of Occupational Safety and Health, Cincinnati, 1999)

"Stress is the reaction people have to excessive pressures or other types of demand placed on them." (Managing stress at work: Discussion document, United Kingdom Health and Safety Commission, London, 1999)

"Stress is a combination of physical and psychological reactions to events that challenge or threaten us. In normal circumstances, the stress response is a powerful protective mechanism that allows us to deal with sudden changes, dangers or immediate demands. In abnormal circumstances, stress overwhelms our protective mechanisms, leading to serious negative health outcomes" (Canadian Union of Public Employees. (2003)

Role ambiguity (RA) is a situation in which associates are unclear about the goals, expectations, and/or requirements of their jobs. It has been shown to have even stronger negative effects on job motivation and performance than role conflict. It also has a stronger relationship with tardiness, absenteeism, and 
turnover than role conflict. Ambiguity on the job creates tension and anxiety (Jackson \& schuler 1995). Role Conflict ( $\mathrm{RC}$ ) is a situation in which different roles lead to conflicting expectations. It is the degree of perceived incongruence or incompatibility of organizational expectations associated with job performance that result in increased levels of job stress. A typical example of role conflict and its connection to stress is provided in the case of flight attendants after the September 11, terrorist attacks (Barnes, B. 2003). Before the attacks, the flight attendants' role focused on providing services to passengers-"service with a smile." However, since September 11, flight attendants under federal rulings have been required to perform extraordinary security procedures and to scrutinize passengers.

Role Overload ( $\mathrm{RO}$ ) this occurs when there is a definite imbalance between job tasks required of an associate and the time allocated to complete those tasks resulting in increased levels of job stress. This could be quantitative (too much work) or qualitative (work is too complex). Research suggests that qualitative overload creates much more stress than quantitative overload. For instance, qualitative work overload has been found to create greater depression, less enjoyment of work, and greater hostility (Shaw, J. B., \& J. A 1985).

Resource Inadequacy (RI) is a situation where there may be too few people, too little support, inadequate material to accomplish a task, thereby placing pressure on the person who has responsibility for the task. People may also experience job stress when they lack needed resources. (Jamal, M. 1984). Having inadequate resources makes it difficult to accomplish tasks effectively and efficiently and can, therefore, increase job demands or lessen control.

Monitoring $(\mathrm{M})$ is when associates' behavior-both work-related and non-work- related are strictly tracked electronically by the organization. The recent developments in technology have led to an explosion of stricter monitoring of associates' behavior. Organizations can read associates' e-mail, detect what web sites they visit, listen to phone conversations, and keep track of any work they do electronically. Monitoring can cause associates to experience increased demands and loss of control at the same time, making monitoring extremely stressful (Aiello, J. R., \& Kolb, K.J. 1995)

Job Autonomy (JA) is the degree of control over jobrelated activities an employee feels he or she possess (Wang \& Netemeyer, 2002).

\section{Emotion-Focused Coping}

It has been acknowledged for years that job stress produces negative emotions (Kahn, Wolf, Quinn, Snock, \& Rosenthal, 1964). More recently, Goolsby (1992) proposes that the magnitude and direction of the consequences of job stress for sales force personnel are partially determined by the coping strategies available to the individual. Emotional intelligence (EI) is a form of self-management of emotionally-based displayed behavior. EI is the ability of a person to manage his/her own emotions and to perceive and manage the emotional responses of other individuals (Salovey \& Mayer, 1990).

\subsubsection{Theoretical Framework for the Study}

To empirically examine the influence and the relationship of workplace stressors, the following framework is used (Figure 1.1 below)

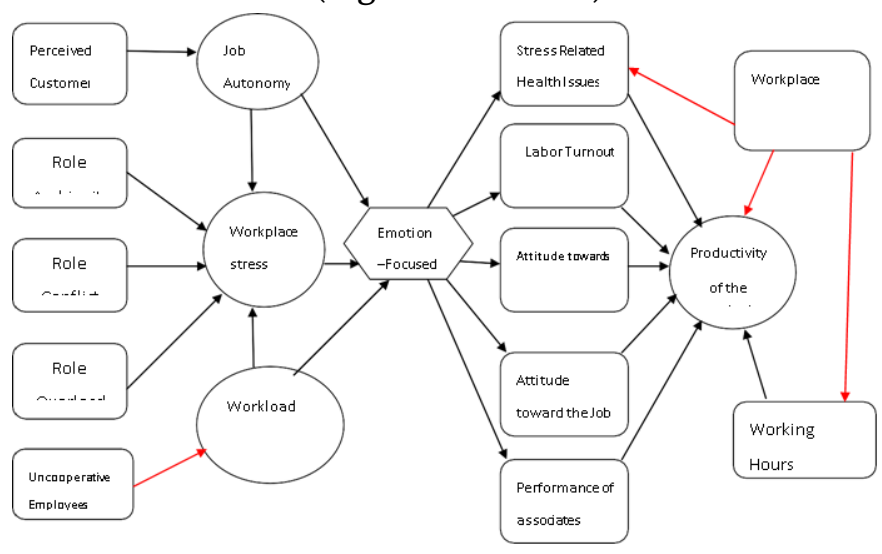

Figure 1.1 1 Structural Model: Job Stress at Service industries 
Previously examined significant Relationship

Under Examined Relationship

\subsubsection{Highlights of the Model above}

The model presented in Figure 1.1 gives a pictorial view and understanding of the theoretical framework of this research work. In this section, keywords presented in the model have been elaborated and further explanations have been given on how the model works. The model shows some stressors that are likely to cause stress to service personnel and their relationships are discussed in further detail in the next chapter. The model shows three major causes of stress which are typical organizationally-based and they include (JS) [i.e., role ambiguity (RA), role conflict (RC), and role overload (RO)], their relationships have been examined by other researchers in different perspectives but for the sake of this studies we will re-examine them to suit this research work.

Moreover, the model highlights factors such as Emotion-focused coping (EFC) which helps to understand how individuals respond to stressors and how some personality types are more prone to stress than others. Researchers have proposed factors and mediating influence on the identified emotional, attitudinal, and physical outcome on employees' behavior at the workplace. There are also additional constructs such as Labor turnout (LT) and health of associates (HA) which have been examined to find out their impacts on the organization's performance and productivity as well.

There are also three additional constructs in the model which include job autonomy, (JA) perceived customer demands (PCD), and physical consequences (PC) and their proposed relationships and outcomes have been reexamined in the current study to enable us to decide and draw reasonable and effective conclusions that would be beneficial to not only the service personnel of Kingstel hotel but to all management and staff in the service industry.

Moreover, the researcher has introduced new variables such as uncooperative colleagues (UC), workload (W), organizational and individual workplace stress management practices (SMP) stressrelated health issues (SRHI) and working hours (WH) of which further examination is carried on to prove their relationship in this research work.

\subsection{Research Questions}

The following research questions will help analyze the effectiveness of workplace stress management practices at Kingstel Hotel and how working hours and productivity are affected as well. It will also help to analyze how stress affects the health of associates and would guide the current research endeavor and the development of the hypothesized relationships between the models' of the various constructs.

1. To what extent does the lack of personal stress management practices for service personnel at Kingstel Hotel result in health issues related to job stress?

2. To what extent do the uncooperative behaviors of employees contribute to an increase in workload at Kingstel Hotel?

3. To what extent does the organizational stress management practices affect working hours at Kingstel Hotel

4. To what extent do individual stress management practices help to reduce stress at the workplace?

5. To what extent do organizational stress management policies help to reduce the stress of associates?

\subsection{Limitations of the study}

The study was conducted at Kingstel Hotel in Takoradi, a three-star hotel located in a very plush 
area of Sekondi-Takoradi the oil city of Ghana which is highly perfected for the business and leisure travel, and therefore there is high pressure on hotels than that of other cities. This makes the stress level of employees over here higher than those workers where there is less pressure. Moreover, the study was carried on only the management and staff members of Kingstel Hotel but no other employees of different organizations were assessed therefore findings of this study are limited to only the management and staff members of Kingstel Hotel Limited. Also, insufficient funds prevented further studies in other areas which are equally important.

Moreover, the researcher does not assure 100\% reliability of data used for this study, due to human error in the data collection process the researcher can assure $70.1 \%$ reliability of the data used.

\subsection{Research Motivation}

Workplace stress has become one of the prominent factors which affect managers and staff mostly in the service sector. It spans from profit-making organizations through non-profit making organizations to households. That is to say, stress has become a universal problem and it affects people from all aspects of life.

The service industry has been one of the stressful sectors in business organizations due to the nature of the job and the service they render. Employees of organizations such as hotel management, banking, telecommunication, and the health sector deal directly with different clients who have different needs, different emotional background and different levels of satisfaction. The most intriguing fact is that customers perceive the quality of their service with the level of satisfaction they receive from them, therefore service personnel has to first of all control their emotions before they can handle the emotional desires of their clients and satisfy their desires.

As such, the management of organizations works so hard to maintain the image of their organizations by strictly monitoring the behavior and work conducts of associates at the workplace. This is necessary because the service personnel play a pivotal role in maintaining the organizations' public image since they provide the service link between their organizations and their customers as well. For instance, in the case of verizon's call- center, associates are strictly monitored electronically to know their daily routine at the workplace. This makes it very stressful for service personnel since it increases their workload and lessens their control. (Aiello, J., \& Kolb, K.J. 1995)

Moreover, most organizations in this sector do not have effective workplace stress management practices as well as personal stress management practices, especially those in the underdeveloped and developing countries. Therefore, the researcher is motivated to survey Kingstel Hotel to find out how effective are the organizational and personal stress management polices at the hotel. And also propose effective ways of managing stress at the hotel.

We always have great concern about controlling, organizing and directing the activities of the organizations' human resources to increase productivity and achieve an organizational goal, but the workplace has been a major challenge to this ambition in most organizations.

It is upon this undeniable fact that the researcher have taken the initiative to conduct a study of employees to find out better and appropriate means of managing stress for management and staff of business organizations especially those in the service industries and hence creating a stress-free working environment at the workplace. Knowledge of stress management could be beneficial to both profit-making organizations and non-profit-making organizations. For instance, it can provide a competitive advantage for a not-for-profit organization as only a limited number of not-for-profit firms embrace a market orientation philosophy (Cano, Carrillat, \& Jaramillo, 2004). 
Over the years, marketing researchers have examined antecedents and consequences of job stress at the service encounter from a sales force management perspective (e.g., Behrman \& Perreault, Jr., 1984) and, more recently, the consumers' perspectives (Folkes \& Patrick, 2003) to the neglect of the service personnel's perspective. Ignoring the service personnel's perspective of sources of job stress, how emotions are self-managed, and stress at the service encounters only allows us to see a small portion of the job stress picture. That is why this study throws more light on workplace stress from the service personnel's perspective.

This area of study is of higher interest and wellmotivated to research into since service attitude and personnel's relationship with customers play a vital role in building and maintaining a higher organizational image. For instance, customer satisfaction and repeat purchase are determined solely by job performance at the service encounter (Bowen \& Schneider, 1985), understanding the roles of job stress and self-management of emotionally-based display behaviors at the social service delivery encounter are extremely important. Service providers that are better equipped to handle emotionally stressful situations at the service encounter should improve the service encounter and, hence, service quality and customer satisfaction.

Moreover, the negative impact of job stress on physical conditions and prosperity of workers is a major issue in the developed nations, the experts from the developed countries like European Union, Japan and America and even from the developing nations focused on job stress and its impact on health of employees (Kawakamii \& Haratani, 1999). Physical, mental and behavioral stress is created which will lead to the lasting results i.e. depression, alcohol abuse, failure, physical diseases and other harmful outcomes (Bickford, 2005). But it's quite unfortunate that stress and its impact on the health and performance of associates in the service industry have received less attention in developing and underdeveloped countries.
Therefore, by this study, the researcher calls to the attention of management and staff in the service providing industry in Ghana especially and the rest of the world the consequences of workplace stress on associates performance, the productivity of the organization as well as the health of associates.

\subsection{Innovation of the Study}

There is no such thing as a 'pressure-free' job. Some pressures can be a good thing, but people's ability to deal with pressure is not limitless. Excessive workplace pressure and the stress to which it may lead can be harmful; they can damage your performance and undermine health and well-being. It is upon this reason that this research gives a vivid approach and highlights that it will facilitate service personnel with a better understanding of stress and suggest some effective ways of managing them. Eliminating pressure from work may not be possible or desirable but controlling harmful and unnecessary levels of stress will help keep you fit and healthy and enable the organization to achieve its goals.

This study offers a practical guide that has been designed to equip service personnel with adequate control over unwanted physical, emotional and psychological reactions and empower them to take charge of how they want their work and life to be. It aims to encourage and support service personnel to get involved in learning and using the best and most suitable ideas and techniques to help them deal with pressure and stress, and also throw more light on the possible causes, effects and practical remedies for stress management to service personnel in the service industry.

With the knowledge gained from this study, social service practitioners have the opportunity to make informed decisions to manage the social service delivery encounter. Moreover, some of the insights gained from the current study may provide invaluable insights for similar service encounters where imposed 
emotionally-based behavior display rules are employed to ensure service quality performance.

\subsubsection{Scientific Interest}

The researcher's interest is directed to the stressors at the workplace by focusing on the management and staff of Kingstel Hotel Limited in Ghana which falls under the service industry. Here we would find out how the theoretical approach to stress management is practiced at Kingstel to help in stress management for management.

The study will help to identify the factors that cause stress at the workplace and how it affects productivity, this is because if structures are put in place to manage workplace stress, and employees are furnished with the right resources for jobs assigned to them, role ambiguity is dealt with, personal and organizational stress management practices are strictly adhered to as well as the right of employees are respected it will contribute greatly to increase in productivity and the profitability of the organization. This study will allow us to master strategies and mechanisms which will help to manage workplace stress and eventually make the workplace a healthy and a happier place for employees of Kingstel Hotel and other service personnel in the service industry.

\subsubsection{Academic Interest}

This paper will be a research work that will focus on the management of workplace stress and its impact on productivity and performance of Kingstel Hotel which will base primarily on the management and staff of the company. It will be a document that will highlight accurate, qualitative and verifiable data that can be used as a secondary data by my future colleagues who would like to conduct further research in this area.

\subsubsection{Socio-Economic Interest}

The fundamental social and economic interest of this study is to enlighten the entire management and staff of Kingstel Hotel the ardent effect of organizational stress on productivity and suggest effective ways of managing them. It will also serve as a reference point for personnel with managerial positions in the service sector as well as those in both profit-making and nonprofit making organizations.

\subsection{Organization of the Study}

This research work is divided into six major chapters with subdivisions as follows; Chapter one is divided into the background of the study, statement of the problems, purpose of the study, Research questions, motivation of the study, the significance of the study and organization of the study.

Chapter two consists of a Literature review on workplace stress management in the service industries, teamwork and uncooperative attitude of employees in an organization.

Chapter three looks at the methodology of the research, the population and sample of the study, as well as organizational summary of Kingstel Hotel Limited, chapter four covers the data analysis and correlation analysis with the use of SPSS. Results and discussion on workplace stress were done in chapter five. The study presents the recommendations and conclusions in chapters six.

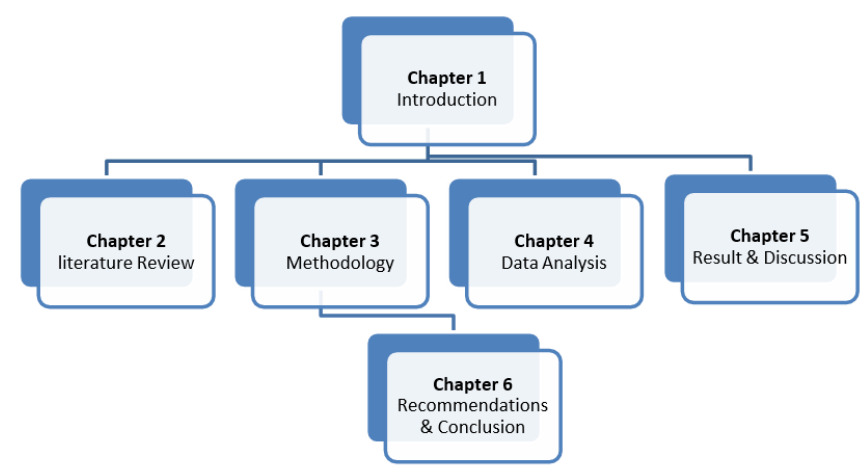

Figure 1.2 1 Organization of the study

\section{LITTERATURE REVIEW}

Tired faces, embittered looks, unwillingness to communicate with colleagues, constant dissatisfaction and in the end the decreasing of the overall working results and poor performance is the picture you often see in organizations with poor stress management plans. Various literature review focus on examining 
the relationships between job stress and intention to leave, it is intuitive that not everyone dissatisfied with his or her job is also dissatisfied with the organization. As such, the current study also examines the extent of how workplace stress affects the health and productivity of service personnel in the service industry.

In an attempt to better understand the proposed relationships presented in Chapter One, this chapter presents an overview of the research relevant to the proposed model and highlights the sources of job stress, mediators, and consequences for frontline social service personnel and the organization. Hypotheses are formed based on the literature and are presented in this chapter.

\subsection{Concept of Workplace Stress}

It is clearly understood that, though everyone faces stress at least once in life, it is still difficult to define the term stress. Through the centuries the concept of stress has been changing, obtaining new meaning or returning to the old definitions.

The problems created because of workplace stress are not limited to a particular profession or a particular country; it has caused long-term effects everywhere in the world (Mark, G. M. (2008).

Various pieces of literature on workplace stress try to analyze stress and disease relation from two different perspectives, which is from psychological to physiological problems and from the biological illnesses to mental disorder. That is to say, at different periods conditions like hysteria, passions, vapors, nerves, neurasthenia, worry, mental strain, and tension have been put forward as significant contributors of or explanations for disease. Through a review of literature, it was observed that life brings a lot of surprises and put us in difficult condition every day, succumbing to great stress which leads to a disease, and it does not matter what century it is (Dewer 2002, Abbott 2001).

However, numerous researchers have researched and come up with various explanations using the Workplace demand-control module. This is because the concept of workplace stress is better explained with the use of a demand-control model since this offers a practical and clearer understanding of workplace stress. We also noticed from other literature that, workplace stress or job stress occurs when associates perceive the demands of the workplace to outweigh their resources for coping with those demands. These are hereby illustrated by one of the popular modules of workplace stress- the demand-control model which is often known as the job demands-job decision latitude model (Karasek, R. 1979.)

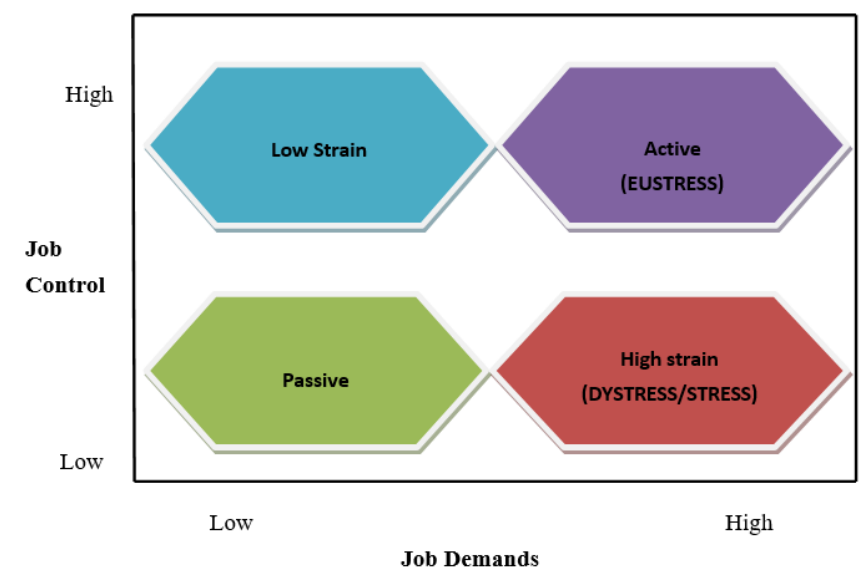

Figure 2.1 1 The Demand Control Module of Workplace Stress

Source: Karasek, R. (1989)

\subsubsection{The Demand-Control Support Model}

From the demand-control model above, when job demand is low and job control is high, the skills of an employee may decrease. Another aspect of this model was social support at work (Johnson \& Hall, 1988). Most researchers accept the fact that both demands and control are important functions in explaining stress. From the review of literature, it was observed that the job demand-control model is a model of job 
stress which is broadly used to show the relationships between job stress and employee health. And the central theme of this model is that stress occurs when employees have high demand and low job control. Also, a high level of stress will affect negatively to the health of an employee. When job demand is low and job control is high, the skills of an employee may decrease. Research on the demand-control model has yielded mixed results. This is because some researchers are of the view that people in the highstrain condition are more prone to experience stressrelated health problems, such as coronary heart disease and high blood pressure. Karasek, R. (1979). Johnson \& Hall, (1988) came with another aspect of this model which is about social support at work. This demand control support (DCS) model states that the main cause of work stress is work content. From their analysis, they identified two components of work content which are employee's feelings about the job tasks that he has to perform at the job (job demands) and employee's feelings about the level of control that he has on these job tasks (job control). It is seen that these two components are closely related to each other and the stress level of an employee will be determined by these components. Moreover, in a situation where there are high job demands and less control over these job demands it will consequently result in a high level of job stress as illustrated in the module above. In 2005, a third component of the social support was added which lead to an updated version of this model. This new addition was to mediate the extent of job stress but not to eliminate it. This model has been used efficiently to foresee mental stress and heart diseases threats (Bickford, 2005).

Research indicates that there are two hypotheses in DCS model which include strain hypothesis states that, high-stress jobs result in poor health employees, and demands, support, and control have high independent effects and buffer hypothesis which is the negative effect of high job demands is moderated by job control and social support. Strain hypothesis is fully supported by results whereas the support for buffer hypothesis is ambiguous (Van der Doef \& Maes, 1998).

Again, there is a hypothetical support from previous literature which shows that the

demand-control theory clearly explains the working conditions which are the major contributive factors to stress. This model has the ability to accurately anticipate negative effects on the health (Sharit \& Salvendy, 1982). When comparing with the PersonEnvironment fit model, Baker (1985) states that Karasek's Demand-Control model is appropriate because of the concept of control which is different from demand and measured as a separate variable. Demand and control are the individual variables which need to be reconsidered and analyze their differences and effects of them both jointly and separately. This model explains the new variable in the forecasting of stress as control is not evaluated as an independent variable in the Person-Environment fit model. Another attractive characteristic of this model is the comparative clarity and stinginess.

Some other concerns of the DCS model are that it focuses on the demand mostly form work burden perspective, but not on other demand types (Cox et al. 2000) and that the control concept has various dimensions but this model narrowly defines it (Carayon, 1993 cited in Cox et al. 2000). Parkes (1989) defines control types that are not mentioned in the DCS, that is, it sees control as an important component of the working environment which is from the individual perceptions on how much work can be controlled and faith on the extent to which serious effects can be managed.

Additionally, review of literature made it clear that the DCS model offers a practical support for primary level interventions (work characteristics) but this is debatable that it can advise on secondary level 
interventions (measures which focus individuals i.e. to give

training for the stress) (Mark, 2008). With the critical analysis of the DCS model, it is observed that some factors of it are important and ignores the effects of common organizational issues e.g. Individuals may have high control over job tasks or low job demands but clashes among subgroups, imperfect managing skills, depends on age or gender bias.

Nonetheless, the DCS model does not explain the causes of the stress but suggests some basis of job redesign which will in effect help to change the demand, control and support levels on an organization. But it is also clear that the nature of some jobs can naturally not be altered like how the model suggests. Mark in 2008 stated that "it will be reasonable to prepare employees how to cope and to improve belief on their abilities, management of the time, information of favoritism matters, giving feedback opportunity and more reward". As such this study tries to review other literature to come out with the cause of stress and other important facts that contribute to workplace stress.

\subsection{Sources of Workplace Stress}

Job stress is commonly defined as the harmful physical and emotional responses that occur when the demands of the job exceed the capabilities, needs or resources of the worker. Studies show that employees who feel they have little control over their work in one way or another report higher stress levels.

Work is a fundamental part of human life. A healthy and rewarding job is a sufficient and positive part of people's lives and allows them to feel satisfied and meaningful in their workplace. However, stress will arise when a job does not let the individual to perform to the best of his ability. Occupational stress is the response employees may have when presented with work demands and pressures that are not matched to their abilities and knowledge. Workrelated stress occurs under various circumstances, but it is often seen to be even worse when employees experience little or no support from supervisors and colleagues (WHO, 2017). According to the APA, the top stressors for people in the workplace, in order of importance, are:

Table 2.1 1 Workplace stressors

\begin{tabular}{|l|l|}
\hline Workplace Stressors & Percentage Impact \\
\hline Low salaries & $43 \%$ \\
\hline Heavy workloads & $43 \%$ \\
\hline $\begin{array}{l}\text { Lack of opportunity for } \\
\text { growth and advancement }\end{array}$ & $43 \%$ \\
\hline Unrealistic job expectations & $40 \%$ \\
\hline Job security & $34 \%$ \\
\hline
\end{tabular}

Source : Health Advocate, Inc

The American Psychological Association (APA) identified some major sources of workplace stressors that affect the employees at the workplace as indicated in Table 1.1 above. This study has analyzed and summarized these stressors and their degree of impact on employees. Again, the researcher have also reviewed various literatures and outlined other stressors that have a higher possibility of causing stress at the workplace and their impact on the health of associates, productivity and the organization has also been outlined in this study.

\subsubsection{Previous studies on $\mathrm{RO}, \mathrm{RA}$, and $\mathrm{RC}$ as workplace stressor}

Moreover, research indicates that, from the beginning of the research work of Jacobson, Charters, and Lieberman (1951), there has been a series of literature in various fields such as management (Bedeian \& Armenakis, 1981), marketing (Behrman \& Perreault, 
Jr., 1984; Singh et al., 1994; Walker, Churchill, \& Ford, 1975), organizational behavior (Miles \& Perreault, Jr's., 1976) and psychology (Netemeyer, Johnston, \& Burton, 1990) which have elaborated on the workplace stress from an organization point of view. Meanwhile, various pieces of literature have revealed that role ambiguity $(\mathrm{RA})$, role conflict $(\mathrm{RC})$, and role overload $(\mathrm{RO})$ have been the major source of workplace stress. From the study of Miles and Perreault, Jr. (1976) RO was classified as a type of RC and does not need to be separated as an individual construct. In recent studies, Singh, Goolsby, and Rhoads (1994) came up with a theoretical approach as a mediator to highlight the relationships between role stressors, burnout, and job outcomes. Upon their research work, an emphasis was made on role overload as one of three core sources of job stress that when combined with other sources of job stress (e.g., emotional labor and perceived customer demands) may cause a cumulative dysfunctional effect on outcome variables.

Research indicates that the theoretical framework proposed by Bedeian and Armenakis (1981) clearly identifies the significant relationship which exists between RA and RC and its direct impact on job satisfaction also contributes greatly to job tension. Moreover, the industrial setting of Walker, Churchill, and Ford's research work in 1975 focuses on metaanalysis as the key components of job stress for personnel in the service sector and also classify RA and $\mathrm{RC}$ as having some form of correlation with high job performance than any other factors which have been proven by other researchers.

\subsection{Categories of workplace stressors}

Upon review of various pieces of literature, the researcher have categorized the various sources of workplace stressors for easier comprehension by our readers. This approach was very necessary due to the numerous stressors at the workplace; this approach will necessitate deeper understanding and easier identification of workplace stressors. This categorization was made by following the research work conducted by Cooper and Marshall (1976) where workplace stressors were categorized into six major groups which have been illustrated in a table below as follows:

Table 2.2 1 Categories of workplace stressors

\begin{tabular}{|l|l|l|}
\hline No. & $\begin{array}{l}\text { Categories of } \\
\text { stressors }\end{array}$ & $\begin{array}{l}\text { Example at the } \\
\text { workplace }\end{array}$ \\
\hline 1. & $\begin{array}{l}\text { Stressors intrinsic } \\
\text { to a job }\end{array}$ & $\begin{array}{l}\text { workload and time } \\
\text { pressure }\end{array}$ \\
\hline 2. & $\begin{array}{l}\text { Stressors due to } \\
\text { relationship at } \\
\text { work }\end{array}$ & $\begin{array}{l}\text { Interpersonal } \\
\text { animosity, poor } \\
\text { leadership }\end{array}$ \\
\hline 3. & $\begin{array}{l}\text { Stressors due to } \\
\text { roles in the } \\
\text { organization }\end{array}$ & $\begin{array}{l}\text { Role ambiguity, role } \\
\text { conflict }\end{array}$ \\
\hline 4. & $\begin{array}{l}\text { Stressors related to } \\
\text { career } \\
\text { development }\end{array}$ & $\begin{array}{l}\text { Job insecurity, } \\
\text { thwarted ambition }\end{array}$ \\
\hline 5. & $\begin{array}{l}\text { Stressors due to } \\
\text { organizational } \\
\text { structure } \\
\text { and climate }\end{array}$ & $\begin{array}{l}\text { Politics, lack of } \\
\text { participation }\end{array}$ \\
\hline 6. & $\begin{array}{l}\text { Stressors at the } \\
\text { work-home } \\
\text { interface }\end{array}$ & $\begin{array}{l}\text { Family problems, } \\
\text { financial difficulties }\end{array}$ \\
\hline
\end{tabular}

Source: Cooper et al., 2001

The buildup of this well-established categorization of workplace stressors as illustrated in table 2.2 above offers perfect integration of the previous research work of stressors from the individual perspective by Cooper et al., 2001. Through a review of literature, it was realized that this categorization by cooper simplifies and offers a vivid explanation to the various stressors at the workplace which also enhances better understanding for all. Mostly attention of most people is much focused on stressors such as workload and pressure at the workplace but this literature has highlighted other aspects such as interpersonal 
animosity, poor leadership, job insecurity and the likes which management of the service sector gives less attention to.

\subsection{Stress and teamwork}

Prior to the study and analysis of various articles and pieces of literature on a multilevel approach to factors that contributes to team stressors, a review was made from the perspective of different disciplines and the research works which have been conducted with the subject matter. According to the best practices of Hodgkinson \& Ford, 2014; Newman, Ucbasaran, Zhu, \& Hirst, 2014; Short, 2009, a step by step search was made to identify the possible combinations of the relevant key terms in the context of "team", "group", and "collective," moreover, other terms such as "stressors," "demand," and "stimuli" along with specific stressors such as "time pressure," "workload," and ambiguity were analyzed in Web of Science, EBSCO (Business Source Complete, PsycARTICLES, and SocIDEX), and Google Scholar. Several articles and research papers were screened by reading through their abstracts to broaden understanding of the topic.

The researcher understood from the studies that the current complexity of the workplace in this contemporary world, the need to work in teams has become so essential for the achievement of organizational goals. It is obvious that that working in teams in an organization offers several benefits to both the organization and the employees as well. This is because employees benefit from different skills and knowledge from others in their team and make the accomplishment of tasks very easy and successful. On the other hand, working in teams in an organization contributes greatly to the stress of team members. Therefore there have been several articles and an increased number of publications where researchers have tried to analyze how teamwork contributes to stress and the relationship that exists between teamwork and stress. (Weiss \& Hoegl, 2015). James
Driskell and Eduardo Salas (1991) published their seminal work on collaborative decision-making under stress. Such, numerous bodies of researchers have conducted series of investigations on stressors and have defined it as "the events or properties of events (stimuli) that are encountered by individuals" (Cooper, Dewe, \& O'Driscoll, 2001, p. 14) - from the team perspective. Cannon-Bowers \& Salas, 1998 gave a comprehensive overview of team stressors. A review of the literature indicates that team stressors have received heightened attention in a lot of journals Maruping, Venkatesh, Thatcher, \& Patel, 2015; Sacramento, Fay, \& West, 201. Moreover, thorough studies on team stressors have proven to have a link with team performance Drach-Zahavy \& Freund, 2007; Pearsall, Ellis, \& Stein, 200, also cross-level studies have discovered how team stressors translate into performance-relevant attitudes and behaviors of team members Kozusznik, Rodríguez, \& Peiró, 2015; Westman, Bakker, Roziner, \& Sonnentag, 2011).

It is essential to note that, some higher studies have revealed that some team stressors are necessary for team performance whereas other are detrimental Drach-Zahavy \& Freund, 2007; Gardner, 2012; Pearsall et al., 2009 and some cross-level studies have shown that some factors such as exhaustion and engagement of team members depend on the stressfulness of team's climate which ranges from distressed to eustressed; Kozusznik et al., 2015. Most findings also show that stressors at the individual level affect individual performance, engagement and commitment Bakker, Demerouti, \& Sanz-Vergel, 2014; LePine, Podsakoff, \& LePine, 2005; Podsakoff, LePine, \& LePine, 2007.

\subsection{Limitations of the Current Approach to Workplace Stress}

Various marketing researchers have examined the antecedents and the impacts of stress from the sales forecast point of view. Researchers such as Behrman \& Perreault, Jr., 1984 and Folkes \& Patrick, 2003 are 
examples. Their researches fail to assess stress from the service personnel's point of view. Obviously, when the sources of workplace stress are ignored from the perspective of service personnel and only how emotions are self-managed are considered, it only gives us a narrow view of stress.

Moreover, it's not enough to analyze only the attitudes and the activities of other group members that contribute to workplace stress. It is upon these reasons why that this study research further and analyzes the relationship and the impact of workplace stress on other factors such as the performance of associates, labor turnout of associates and the productivity of the organization. Further studies are also carried to reanalyze how workplace stress affects the health of associates.

Throughout the extensive review of literature, almost all pieces of literature assessed were silent on some personal stress management practices which can help service personnel to deal with workplace stress. Another limitation is that gaining insight into the relationship of self-management of emotionally-based display behavior of service personnel will only enable management to decide whether to impose rules that help to shape emotionally-based behavior for associates in the service industry. If the managerial intervention well determined to improve job performance then the next natural step is to determine where, when and which interventions are appropriate Bitner, Booms, \& Tetreault, 1990.

Moreover, research indicates that, in a situation where the service personnel perceives that they are unable to meet the service quality that the customer requires it finally results in stress for the service personnel Chung \& Schneider, 2002. For service personnel to meet the desired satisfaction of the customer, they need to adjust the quality of service which they offer to their customers. Bitner et al., 1990. There is empirical evidence from the review which suggests that customer demand is an antecedent of role conflict. Chung \& Schneider, 2002.

\subsection{Theoretical Contribution}

In every organization, it is the human spirit and inspiration that leads associates to apply their human capital to meet the goals of the organization, the human spirit is highly inspired through motivation. Therefore, motivation is essential to almost any aspect of life.

Understanding job satisfaction and work motivation can be key elements to improving productivity. Motive is what prompts a person to act in a certain way or at least develop an inclination for specific behavior (Kast and Rosenzweig, 1985).

According Herzberg's Motivation Hygiene Theory there are some factors known as motivating factors that cause job satisfaction. Therefore when the needs of associates are met at the workplace it will help to increase job satisfaction and reduce both organizational and personal pressure that result in active stress on employees. In order to identify the actual needs of employees and satisfy them accordingly Abraham Maslow in the 1940s proposed a theory in a form of a pyramid which categorized the needs of employees in order of importance.

The psychologist Abraham Maslow exposes his theory of motivation in his article "A Theory of Human Motivation", which was published in 1943. The pyramid consists of five main levels. According to Maslow, we should first seek to satisfy each need of a given level before thinking about the needs at the next higher level of the pyramid. For example, it is better to seek to meet physiological needs before security needs: that is why, in a situation where our survival would be at stake, we would be willing to take risks.

For the purpose of this study, the motivational needs of employees have been discussed at each level to assess its significance and how it can help to meet the individual needs of employees at Kingstel Hotel and employees in the service industries. 


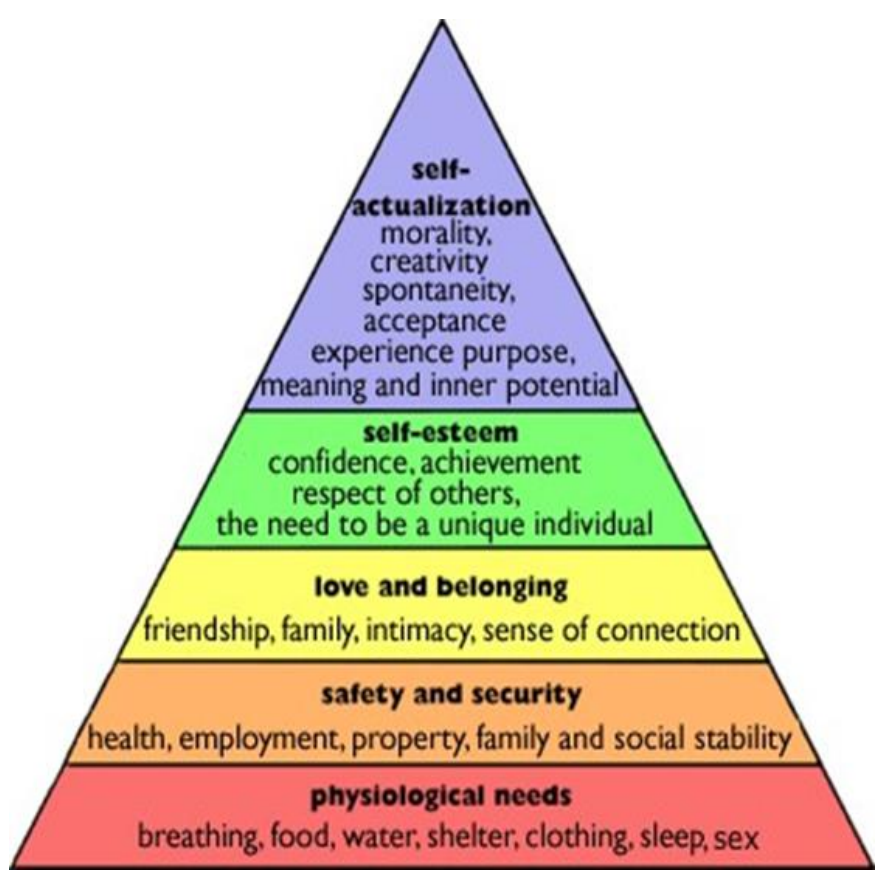

Figure 2.2 2: Maslow’s Hierarchy of need

\subsubsection{Physiological Needs}

Physiological needs are those related to the maintenance of homeostasis of the body (breathing, drinking, self - nurturing, eating, sleeping, warming): the regulation of the major biological balances necessary to maintain a state of physical health. Necessary for the survival of the person, they are imperious and can prevail on the conscience if they are not satisfied. The presence at this level of the need to procreate is subject to discussion. The latter, useful for the species, does not necessarily appear to be present in any individual, which makes the interpretations diverge. Therefore when the physiological needs of employees of Kingstel Hotel are met it will increase their satisfaction level at work and eventually energize them to give out their best.

\subsubsection{Security Need}

For associate to have a sound mind and work diligently, their security needs to be catered for by the organization. These needs are those that are linked to the aspiration of employees to be physically and morally assured of. They cover the need for shelter (housing, home), income and resource security, physical security against violence (delinquency, assault, etc.), moral and psychological security, family stability or, at least, some emotional security and social security (health). It will be noted that the satisfaction of the aspirations for security as well as the satisfaction of physiological needs are inscribed in human rights; this does not mean that any state is already in a position to fully enforce these rights. These needs can be met by ensuring that associates of kingstel Hotel are offered better salaries and incentives which will make them feel more secured and have more emotional stability which will help them to manage their own emotions and manage the emotions of their clients as well.

\subsubsection{Emotional Need of Belonging}

Sometimes referred to as "the need for social recognition", the need to belong to a family or social group is translated into the search for communication and expression. This need for integration into the social bond goes hand in hand with the need for recognition and consideration. The need for love must be taken into consideration. It goes by the proper identity (name, first name), the need to love and to be loved, to have intimate relations with a spouse (to form a couple), to have friends, to be an integral part of a cohesive group, to feel accepted and, logical consequence, not to feel alone or rejected.

This need is manifested by the sometimes atavistic or gregarious behavior of the human being. The majority of individuals would not be able to live without others, solitude experiences show the psychoaffective, behavioral disorders to which a lonely individual is exposed for too long. The deprivation of others in the human being is of the same order as the deprivation of sleep too long, it tends to make go crazy the person who is there diving. Sentences of solitary confinement, or other, are among the harshest sentences, and probably the most dangerous for an individual. 
Moreover, when the emotional needs of associates are satisfied at kingstel hotel it will help to reduce friction among group members and also help to reduce uncooperative attitudes of employees in an organization and hence reduce workplace stress.

\subsubsection{Need for Personal Esteem}

Man needs to develop a self - esteem and to make itself respected by others (estimate). He needs to attend to be recognized, to have a rewarding activity whether in the field of work, or in the field of leisure. It is in particular the need to realize oneself, to value oneself (in one's own eyes and in the eyes of others) through an activity. The human being also needs to make plans, to have objectives, opinions, to be able to express his ideas.

\subsubsection{Need for Personal Fulfilment}

The need for accomplishment of a work or commitment is to allow one's personality to flourish and to be able to fulfill one's full potential. But to achieve this "need for achievement", it is necessary to master all the previous needs. This need could be fulfilled by creating opportunity for promotion and personal development programs at Kingstel Hotel for associates to climb higher to actualize their dreams. This help to increase the job satisfaction level of associates and hence work in a less stressful atmosphere at the workplace.

\section{METHODS AND MATERIAL}

This chapter of the research work presents the methodology used to collect and test how stress actually have impacts on the health, performance and productivity of the organization as well. This chapter is the most important part of the research work because, for effective research work to be done, it demands a dependable and a concrete method of gathering information. For this reason, the researcher has first given clear information on the sample characteristics and the research setting this study.
After that, further explanation of the mechanisms and the techniques which were used in the data collection for this research work has been given. And finally justify why those techniques were used instead of others.

The quantitative and qualitative research approach was used for data collection and analysis in this research work. With the deductive research approach, questionnaires were administered to gather the primary data for quantitative analysis. Again, since this research work combines both inductive and deductive research approaches, the inductive approach would allow me to form hypothesis based on the responses from the respondents through questionnaires and interview techniques. Most business management research work combines both research methods due to the observable objectives and facts and the numerical and perceptive nature of information in recent times. These techniques were also chosen because they allowed for data gathering and information from both primary and secondary source for this research work, the following techniques would be used.

The service industry has been one of the sectors which are prone to stress due to the nature of work and the responsibilities which employees are supposed to execute. Employees in the service sectors such as banking, telecommunications, insurance and hotel management

companies have the higher tendencies of going through some forms of stress since they deal directly with clients with different issues and emotions. That is to say a particular work component may be favorable for the health of an employee such as energy expenses (Fletcher, 1988). For instance, the customer service consultants who work in the customer service center will always need to face a lot of customer complaints which will directly lead them to certain stress level. Therefore, stress management is very essential for employees of these sectors. 


\subsection{Brief History of Kingstel Hotel}

For the purpose of the conciseness and avoidance of ambiguity in this research work, we will streamline our studies and focus on stress management at the hotel management sector, Kingstel Hotel at Takoradi -Ghana, a three star hotel at the oil city of Ghana would be used as a case study. Kingstel hotel is located in a very plush area of Sekondi-Takoradi, oil city of Ghana perfected for the business and leisuretraveler with 60 ultra-modern rooms made up Standard, Deluxe, Superior Deluxe and Executive Suite to choose. Kingstel Hotel provides accommodations with a restaurant, free private parking, free bikes and an outdoor swimming pool. Among the various facilities of this property are a bar, a shared lounge and a garden. The hotel has an indoor pool, fitness center, evening entertainment and a 24hour front desk service. Guest rooms has air conditioning, a flat-screen TV with satellite channels, a fridge, an electric tea pot, a shower, a hairdryer and a desk. Free WiFi is available to all guests, while selected rooms come with a balcony. At the hotel each room has a seating area.

A typical day at work included making room reservation for clients, assisting clients to check- in and check-out meeting with associates to review sales and marketing strategies aimed at improving patronage by clients, outlining personalized strategies to improve individual performance, general supervisory functions, calling potential customers and meeting guests. The hotel also runs 24-hour front desk service for its customers; check-in time is from $1 \mathrm{pm}$ to $12 \mathrm{am}$ whilst the check-out time is from 7am to $12: 30 \mathrm{pm}$. This require much time from employees since they have to serve their customers throughout these hours.

\subsection{Research Setting}

To make the research work more vivid and practical, personnel from the service industry was chosen as the case study, the researcher also strived to find out how stress is managed by managers and employees in developed countries therefore, the management and staff of kingstel Hotel were used as the target population for the study. The sample of the management and staff of the hotel gives a fair representation of the target population for this research work. Kingstel Hotel is a three star hotel located in Takoradi the oil city of Ghana, the west coast of Africa. The study was focused on Africa because throughout the review of literature, it was realized that most articles and research works on stress management and its impact were conducted in an American and European setting, therefore the researcher strived to research into Africa and find out how workplace stress affects the lives of employees in the service industry and how it is being managed by both management of organizations and the associates as well.

Moreover, the service industry is seen as one of the most organizations which are prone to stress since associates have to work on their own emotions and should also have the abilities and the skills to handle the emotions of their clients with different emotional conditions as well. Service personnel represent the image of the organizations in which they work as well as the service which they provide Ashforth \& Humphrey 1993. This is because, customers perceive the quality of service they receive from how they are being treated by service personnel as such they need to exhibit high level of professionalism in their service delivery this makes it more stressful for workers in such organizations. It is therefore prudent to conduct the studies on stress in such organizations to find how they are able to cope with stress and the efforts which managements are making to manage this organizational canker.

\subsection{Populations for the study}

The total population for this study consisted of fiftyfive management members and staff of Kingstel Hotel, the population consisted of fourteen (14) management members, fifteen (15) Supervisors, nineteen (19) and seven (7) intern from the hotel. This population size 
was chosen from the hotel in order to ensure a fair representation and reliability of data. It will also enable me to assess stress and its impact on employees from different perspective. The study will be able to analyze and find out how management members manage stress for associates and some personal and organizational management practices which help to minimize workplace stress.

Table 3.1 1 Job title of Respondents

\begin{tabular}{|l|l|l|}
\hline Job title & Frequency & Proportion \\
\hline Staff & 19 & \\
\hline Management Member & 14 & $34.55 \%$ \\
\hline Supervisor & 15 & $25.45 \%$ \\
\hline Intern & 7 & $27.27 \%$ \\
\hline Total & $\mathbf{5 5}$ & $12.73 \%$ \\
\hline
\end{tabular}

\subsection{Sample and Sampling Procedure}

With regards to the objectives of the study, the sample was taken from Kingstel Hotel. The sample unit was fifty-five (55) service personnel of the hotel. Those who received questionnaire at the hotel included management members, front office personnel, account officers, waiters and waitresses. Those people were selected through no scientific means but for the fact that they represent different levels of the hotel's organizational structure. Also a convenient sampling method was therefore used for the collection of data from other staffs of the hotel.

In addition, the table 3.2 below shows the age distribution of the respondents, this was necessary for us to analyze and find out if stress affects a particular age group more than others. It is clear from the table that $41.82 \%$ of the respondents which represents the greater proportion of the respondents are those employees who ranges between the ages of $26-35$. This is an indication that most of the respondents for this research work are of the youthful population.
Table 3.2 1Age Distribution of the population Source: Field Research Data 2019

\begin{tabular}{|c|c|c|c|}
\hline Range & Frequency & Proportion & \\
\hline $18-25$ & 13 & $\square$ & $23.64 \%$ \\
\hline $26-35$ & 23 & 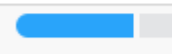 & $41.82 \%$ \\
\hline $36-45$ & 7 & $\square$ & $12.73 \%$ \\
\hline $46-55$ & 7 & a & $12.73 \%$ \\
\hline 56 \& Above & 5 & a & $9.09 \%$ \\
\hline Total & 55 & & \\
\hline
\end{tabular}

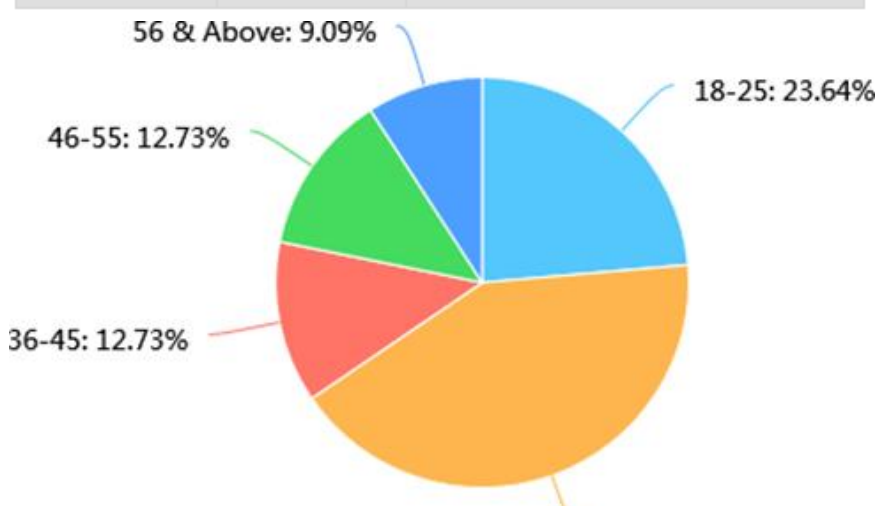

26-35: $41.82 \%$

Figure 3.11 is a graphical representation of the age distribution

Table 3.3 1 Sex distribution of respondents

\begin{tabular}{|c|c|c|}
\hline Sex & Frequency & Proportion \\
\hline Male & 33 & $60 \%$ \\
\hline Female & 22 & $40 \%$ \\
\hline Total & 55 & \\
\hline
\end{tabular}

Source: Field Research Data 2019

Out of the total number of fifty-five respondents, $60 \%$ of the total population are male as well as $40 \%$ being females. This will give us an idea of which sex group are more succestible to workplace stress, and which has the greater ability to cope with stress and manage stress for other as well.

\subsection{Questionnaire Survey Technique}


In this research work I resort to collect primary data as well as secondary data for the analysis and survey therefore Questionnaire would be administered to the management and staff of Kingstel Hotel. As such introductory letter was first sent to the management of Kingstel hotel to seek their consent and also sort permission to use their organization for the case study. After that fellow up calls were made to the authorities of the hotel to sort for their assistance encourage participation in the data collection process in order to obtain timely and legitimate information which will be beneficial to the study.

In order to encourage participation in the data collection process, an extract of the research work highlighting the causes and the consequences of workplace stress was included in the introductory letter. I further assured management of the hotel that an executive summary of the research report and finding would be given to them which offer them a broader view and knowledge about workplace stress and its impact on both employees' health, productivity and the organization as a whole.

\subsection{Questionnaires}

The questionnaires used for this study is made up of both opened-ended and closed- ended questionnaires designed for the management other staffs of Kingstel hotel. The questionnaire is made up of fifty (50) questions of which ten (10) were opened-ended questions constructed for the respondents to give information by themselves, while forty

(40) closed-ended questions were made up of possible answers for respondents to tick.

The main purpose was to establish how service personnel at the hotel as well as the managers of the hotel manage workplace stress and also to assess the effectiveness of personal and organizational stress management practices of the staff and the organization respectively. The research is also to find out whether the service personnel of the hotel are satisfied with the organizational stress management practices at the hotel.
Moreover, we chose to use questionnaires due to its practicality, affordability and timeliness. The researcher used the online questionnaire which is the most economical way of data collection and also more practical way of collecting data. The questionnaires were both multiple choice and open-ended question which offers respondents the chance to pick and choose any answer of their choice and also presents their own idea about question that are open-ended. Through this means, a vast amount of data was gathered in relation to the subject matter within a shorter space of time.

With the online questionnaires system that was used, the geographical location of the respondents was not a problem since they were able to fill them everywhere they are provided they have internet connections. The researcher only sent them a link of the questionnaires and with just a finger click everything was done. Also, the data collected could be used to compare and contrast other research and can also be used to measure change in the organization.

Aside these unprecedented benefits of using questionnaires for data collection there are some limitations which if not well handled it can be detrimental to the data that we collect. For instance, the respondents may not provide 100 percent accurate information in their response due to a lot of factors. As such the researcher assured the respondents that their privacy is highly protected and any information provided would be used solely for the research work and nothing else. The researcher also tried to get the involvement of the authorities of the hotel and this will help in some way for us to get more accurate response from the questionnaires.

In the same way, the number of unanswered questions was very low since most of the questions were multiple choices and the online questionnaire system also helped to avoid this problem by requiring respondents to answer one question before moving to another. To avoid miscommunication and 
misinterpretation of the question by the respondents, simple

and clear questions were used in the questionnaires which will help all the respondents from various educational backgrounds to read and understand.

It is upon this number of benefits that this method for the data collection was used but not other methods. For instance, other methods of data collection such as the direct observation and face to face interview method which seems to provide more accurate information since respondents can ask questions wherever they are not clear was not used due to distance and the cost involved.

\subsection{Statement of Hypothesis}

The following hypothesis was raised to be tested and find out whether they correlate with the variables in our data collection:

$\alpha=\frac{N \cdot \bar{c}}{\bar{v}+(N-1) \cdot \bar{c}}$

H1. Attitude of uncooperative colleagues increase workload at the workplace

H2. Lack of stress management activities at the workplace increase health issues related to stress.

H3. Stress management practices reduces working hours

3.7 Reliability and validity of the research

Research reliability refers to the extent to which the research method used for the study produces stable and consistent results over time. It is a means of finding out if the same instrument is used to measure a variable it will produce same result over time.

To test the reliability of the variables used for the data analysis of this study, the researcher used the Cronbach's alpha, $\alpha$ (or coefficient alpha), developed by Lee Cronbach in 1951, to measure the reliability, or the internal consistency of our research variables. The table below gives a summary reliability statistics of our data with the use of SPSS
Table 3.4 1 Reliability Statistics

\begin{tabular}{|r|l|l|}
\hline $\begin{array}{r}\text { Cronbach's } \\
\text { Alpha }\end{array}$ & $\begin{array}{l}\text { Cronbach's Alpha } \\
\text { Basedon } \\
\text { Standardized }\end{array}$ & N of Items \\
\hline .711 & Items \\
\hline
\end{tabular}

Source: Field Research Data 2019

From the table the Cronbach's alpha is .711 which indicates that $71.1 \%$ of the variance in the scores is reliable variance and $28.9 \%$ is error variance. Meanwhile the Cronbach's alpha of individual variables has been attached to the study as an appendix.

Moreover, the internal consistency reliability is relevant to composite scores, which are the sum (or average) of two or more scores is given as

Where:

$\cdot \mathrm{N}=$ the number of items.

$\cdot \mathrm{c}=$ average covariance between item-pairs.

$\cdot=$ average variance.

\subsubsection{Research Validity}

Research validity is one of the important elements in research work due to the fact that, it enables the researcher to be more confident about the research work which has been conducted in a given field. This is because the assessment of research validity helps to measure how valid is the dated used for the research analysis. Therefore the validity of the primary data used for the analysis in this research work was tested under the three basic kinds of validity to assess how valid the data is and also to enhance quality research work.

The researcher analyzed the face validity, content validity as well as the criterion validity.

Face Validity 
As far as face validity is concerned, the questionnaires used for data collection in this research work were carefully constructed to suit the purpose of this research work. The variables were constructed in way that it will allow respondents to provide the actual information needed for this research work. For instance, variables such as:

1. How often do you have any health issues related to job stress?

2. How well do you cope with job stress on your own?

3. Do you have stress management policies at work?

4. Do you have personal stress management activities?

The answers for these questions above will provide clear information about workplace stress and health related issues as well as the both organizational and personal stress management policies at the workplace which are the major objectives of this research work. This is a clear indication that the face validity of this research work has been achieved for this research work.

\section{Content Validity}

Content validity is about carefully assessing the measurement method used in the research work against the conceptual definition of the research objective. Referencing from the demand and control model in figure 2.1 the definition of workplace stress from chapter two of this study, the researcher realized that workplace stress occur when employees work demand exceeds their ability to control. The respondents proved the content validity of this study by answering that their work demand exceeds their ability to control. $22.22 \%$ have very less control over their work demand, 25.93\% have less control, 25.93\% have normal control over their work, $18.52 \%$ have high control and $7.41 \%$ have very high control over their work. This responds indicates clearly that the management and staff of Kingstel Hotel surfer from workplace stress.
Table 3.51 Response on how respondents job control match their demands?

\begin{tabular}{|c|c|c|}
\hline Range & Frequency & Proportion \\
\hline 1 & 12 & $22.22 \%$ \\
\hline 2 & 14 & $25.93 \%$ \\
\hline 3 & 14 & $25.93 \%$ \\
\hline 4 & 10 & $18.52 \%$ \\
\hline 5 & 4 & $7.41 \%$ \\
\hline Total & 55 & \\
\hline
\end{tabular}

Source: Field Research Data 2019

Criterion Validity

In this research work, the criterion validity was tested by assessing the extent to which our responds gathered from the questionnaires correlate with the variables of the research. For instance, variables such as:

X11: How heavy is your work load X27: Uncooperative colleagues

Were tested and find out that there is a positive correlation between uncooperative attitudes of employees and workload.

Again variables such as:

X42: How often do you have any health issues related to job stress X46: Do you have personal stress management activities?

Were tested and there was a negative correlation between lack of personal stress management activities and health issues related with stress.

\subsection{Documentary Technique}

To successfully collect facts on workplace stress management at Kingstel Hotel, data was collected from both primary and secondary source. This was carried out, based on the data drawn from the questionnaire designed and administered on sampled management members and staff of Kingstel hotel.

3.8.1 Primary Data 
Primary source of data refers to data that is being collected for the first time of project research. In the collection of this data, there is field work, techniques and procedures for collection but due to distance and time the researcher chose the online survey system which is the most easy and efficient means of gathering primary data. As far as primary data is concerned the source of data for this research work was obtained through interviews and questionnaire administration.

\subsubsection{Secondary Data}

Secondary source of data refers to published data that was collected for a previous research, but can also be used for the pending research. In this research work, both quantitative and qualitative secondary data was used so as to enhance better understanding and also produce

quality research work. That is, information was gathered from sources such as articles, publications, reports, and other related literatures were also reviewed to gather enough information and evidence for the study.

This method of information gathering was used due its availability and accessibility. With the help of writers and researchers, there are numerous of information related to the subject that is accurate and accessible for the study. The researcher also made good use of some official statistics from articles, reports and publications for comparison and further analysis.

But that notwithstanding, some information change over time thereby making historical comparison inaccurate for researchers, therefore a critical analysis was made to ensure the quality and the validity of the information obtained for this study. Also, some documents may lack authenticity due to passage of time part of the information might be missing and will be difficult to verify the writers.

Some secondary data also lack true representation of the population and fail to offer researchers with accurate information for research work. Some older information may be deteriorated or might not be well stored for future reference. Additionally, other documents may be deliberately withheld from public accessibility and usage due to some other reasons. All these challenges make it difficult to use secondary data but a careful analysis and a diligent research was carried to review the best data which are useful for this research work.

\subsection{Interview Technique}

Recently, research works in the field of social sciences adopts research methods which are essential in determining the success, validity and reliability of the research work. Due to dynamism of human behavior, social scientists tend to use qualitative research approach so as to enable them to effectively accumulate a detailed account of human behavior and beliefs within the contexts they occur in and to facilitate thorough understanding of human behavior as well (Rubin \& Rubin, 2005). Furthermore, qualitative data are "mostly" collected by researchers through interviews and questionnaires. Therefore, interview

technique was added to the research methodology due to its powerful advantage it offers in eliciting narrative data that allowed us to investigate people's views in greater depth (Kvale, 1996; 2003). The same point of view was expressed by (Cohen et al 2007) add that interviewing is "a valuable method for exploring the construction and negotiation of meanings in a natural setting".

One major reason why the interview technique was used is to allow the respondent to express their views on the given topic. To avoid research bias the respondents were allowed to voice out their opinions in the data gathering which will eventually contribute greatly to the data analysis and findings. the value of interviewing is not only because it builds a holistic snapshot, analyses words, reports detailed views of informants; but also because it enables interviewees to "speak in their own voice and express their own thoughts and feelings" (Berg, 2007: 96). 
As a result the General and Marketing Managers of Kingstel Hotel Limited were interviewed to gather information on the stress management structures that have been put in place in the organization and how they help to reduce stress for the management and staff of the hotel. Other departmental managers of the hotel were not interviewed due to time and resources constraint.

\subsection{The Analytical Method}

At this stage of the research work, the data and information collected were carefully analyzed through interviews and questionnaire from the management and staff of Kingstel Hotel. The analytical work was done with the help of correlation analysis. Correlation Analysis is statistical method that is used to discover if there is a relationship between two variables/datasets, and how strong that relationship may be. Therefore the researcher tried to find out how effective workplace stress management activities and how it correlates with working hours in an organization. The researcher also find out the relationship between personal stress management activities and stress related health problems. Nonetheless, the relationship between how uncooperative colleagues and work load was also analyzed with the use of correlation analysis.

\section{DATA ANALYSIS}

This chapter presents the analysis and findings from the questionnaires and interview results from Kingstel hotel. With the help of correlation analysis the data has been analyzed below

The data listed below may relate to "how workplace stress affect the health and performance of employees and hence productivity of the organization."

$\mathrm{X} 11$, How heavy is your work load

X19, Unreasonable time pressures at work X25, How often do you delegate functions

X26, The existence of factors that contribute to stress at work X27, Uncooperative colleagues

X28, Many emergencies at work
X34, How often do you take work home X35, How many hours do you work in a day

X37, How do you feel about performance of your subordinates X42, How often do you have any health issues related to job stress X43, How well do you cope with job stress on your own

$\mathrm{X} 44$, Do you have stress management policies at work $\mathrm{X} 45$, If yes, what is your opinion on its effectiveness $\mathrm{X} 46$, Do you have personal stress management activities

\subsection{Correlation analysis}

\section{Heatmap for correlation analysis}

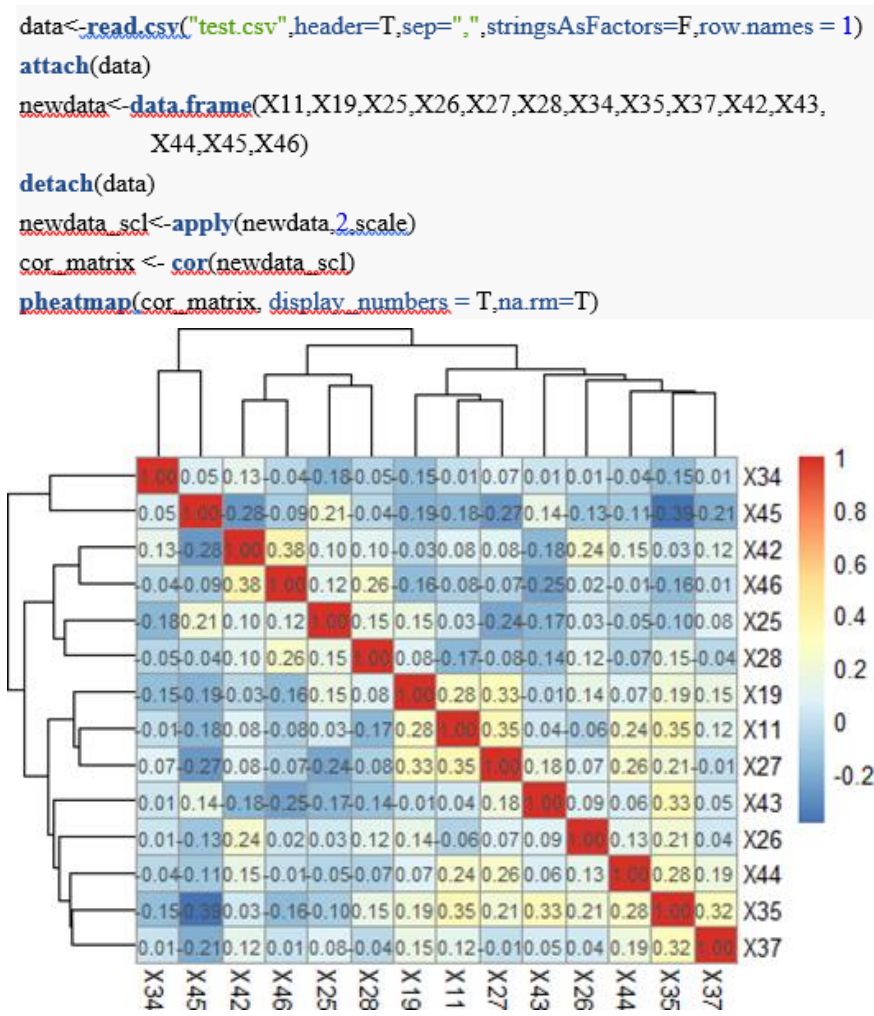

Figure 4.1 1: Correlation values

High absolute value of correlation value is picked up for further analysis

X45 X35

ggplot(newdata,aes $(\mathrm{X} 45, \mathrm{X} 35))+$

$$
\begin{aligned}
& \text { geom_jitter }()+ \\
& \text { geom_smooth(method="lm") }
\end{aligned}
$$

P-value : 0.003015 (significant) cor-value : -0.3927723 


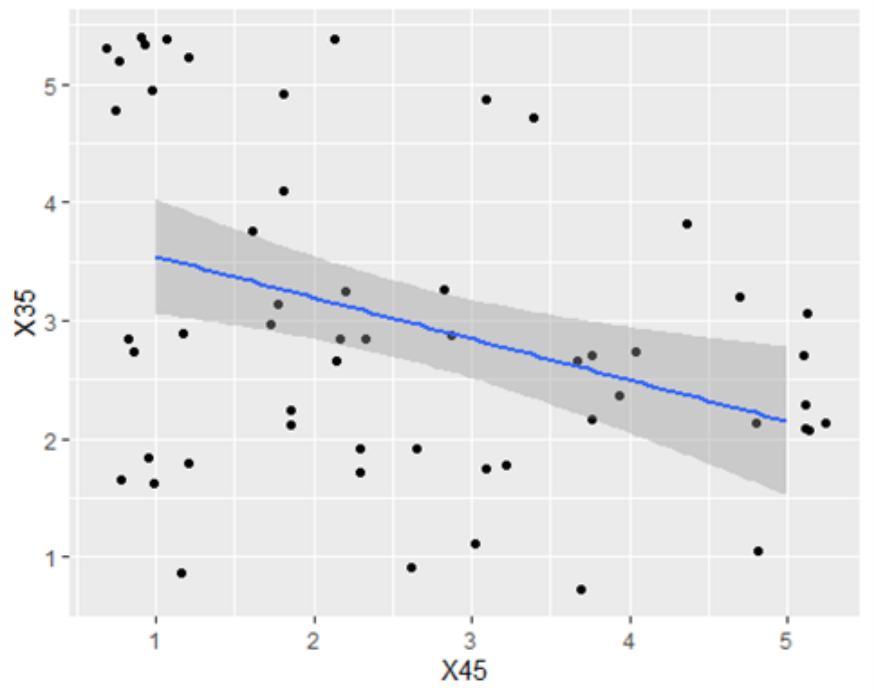

Figure 4.2 1 Effectiveness of workplace stress management policies

cor.test(newdata $\$$ X45,newdata $\$ X 35)$ \#\#

\#\# Pearson's product-moment correlation \#\#

\#\# data: newdata\$X45 and newdata\$X35 \#\# $\mathrm{t}=$ 3.1093, $\mathrm{df}=53, \mathrm{p}$-value $=0.003015$

\#\# alternative hypothesis: true correlation is not equal to 0 \#\# 95 percent confidence interval:

\#\# -0.5959687 -0.1423033

\#\# sample estimates: \#\# cor

\#\#-0.3927723

P-value : 0.003015 (significant) cor-value : -0.3927723

\subsection{Effectiveness of stress management policies}

$\mathrm{X} 45$ : what is your opinion on stress management policies effectiveness? X35: How many hours do you work in a day?

The figure 4.2 above shows the larger X45 and, the smaller X35.

The larger X45 means stronger stress management policies effectiveness at work. Less X35 means shorter working hours of associates.

So this graph shows stress management policies effectiveness at work can reduce work hours. That is to say there is a negative correlation between workplace stress management activities and working hours.

Despite the significant benefits of stress management policies at the workplace, the analysis indicates clearly that it can also reduce the working hours of employees as show in the figure above. Moreover it is worthy to note that healthy and happy employees can use lesser hours to accomplish higher productivity, therefore implementing stress management policies at the workplace may reduce working hours but increase productivity in the long run.

$\mathrm{X} 42 \sim \mathrm{X} 46$

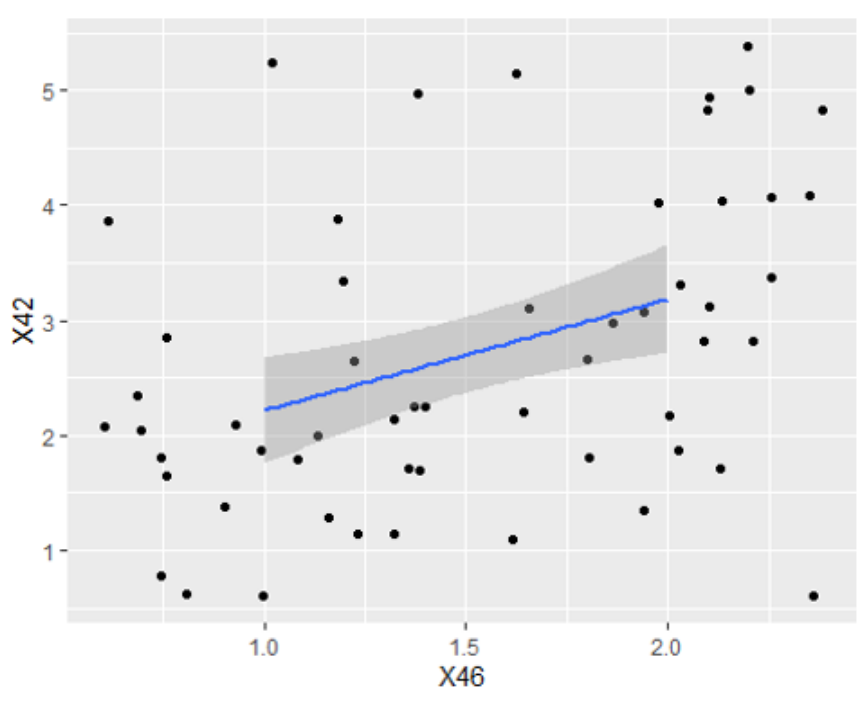

Figure 4.31 : Individual stress management activities

P-value : 0.004692 (significant) cor-value : 0.3758041

4.3 Individual stress management practices

X42: How often do you have any health issues related to job stress X46: Do you have personal stress management activities

The figure 4.3 above shows the larger X46 and, the lager X42. In this case for X46, 0 means Yes and 1 means No.

So this graph indicates that people have no personal stress management activities and it's therefore likely for them to suffer from stress related health issues related to job stress. That is to say, there is a positive 
correlation between individual stress management activities and stress related health issues.

In organizations whereby employees have compact work schedules and limited time for break, people tend to ignore stress management activities due to the fact that, their job requirement exceed their capabilities and time limit. This happens when their job demands exceed their control. This might also result in eustress which can have adverse effect on their health and performance as well. The long run effect of this is absenteeism and low productivity. $\mathrm{X} 11^{\sim} \mathrm{X} 27$

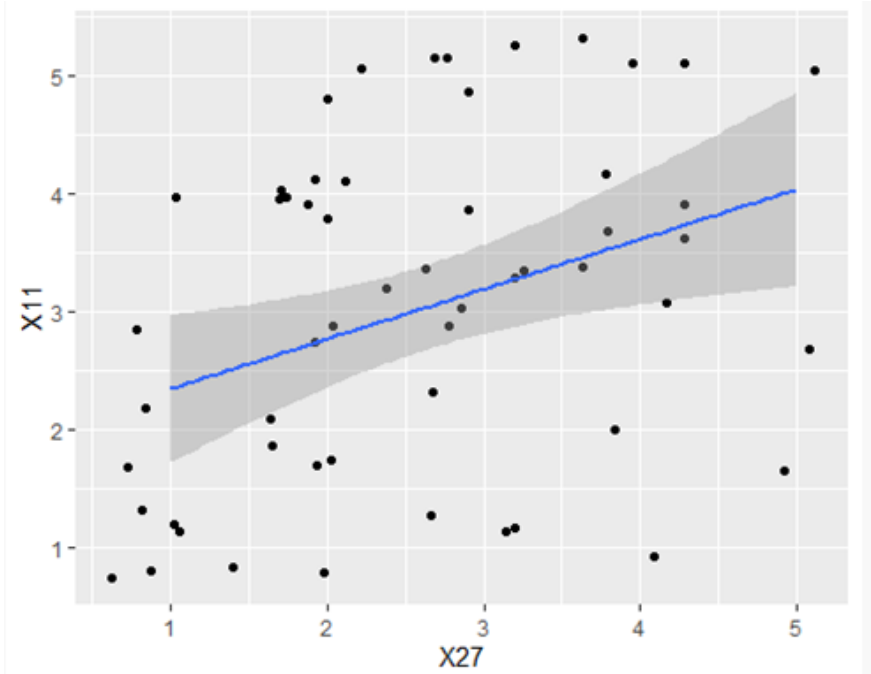

Figure 4.4.1: the result of teamwork in an organization

P-value : 0.008789 (significant) cor-value : 0.3500834

4.4 Impact teamwork in an organization

X11: How heavy is your work load X27: Uncooperative colleagues

The figure 4.4 above shows the larger X27 and, the lager X11.

Numerous articles and publications on teamwork in an organization indicate that the more colleagues in an organization tend to be uncooperative, the heavier work load will be and the higher the chances of suffering from stress. This means that, there is a positive correlation between uncooperative colleagues and work load of employees in an organization.
It is clear from the studies that the current complexity of the workplace in this contemporary world, the need to work in teams has become so essential for the successful achievement of organizational goals. It is obvious that working in teams in an organization offers a number of benefits to both the organization and the employees as well. This is because, employees benefits from different skills and knowledge from others in their team and makes the accomplishment of tasks very easy and successful. On the other hand, not working in teams in an organization contributes greatly to stress of team members. Therefore there has been a number of articles and increased number of publications where researchers have tried to analyze how teamwork contributes to stress and the relationship that exist between teamwork and stress. (Weiss \& Hoegl, 2015)

\subsection{Analysis of Interview Result}

There were 36 questions in the questionnaire which was used for the interview, divided into four parts Occupational status, factors influencing stress, current stress management tools and the interviewee's recommendation for Stress Management. The last one was meant for the individual who are already acquainted with the Stress Management program in practice.

Here, the results of the last three parts are utilized. The first part forms the basis of the introductory information already provided on the interviewee. The results are presented under thematic structure with detailed analysis of the received results from the entire interview. Some words and examples will be quoted in order to show more clearly the point of interlocutor's view in any valuable matter.

\subsection{Factors Influencing Stress at Workplace}

\subsubsection{Occupation and work overload}

The marketing manager answered affirmatively when asked if he has enough power to produce a better performance at his job. He however stated he cannot 
fire or promote any of his associates but rather expected to make formal report to the higher level management recommending persons for such actions. Having worked with the company for six years now and rising through the ranks till his current position as a manager, the interviewee was very confident he had enough experience and expertise to handle his tasks. Workshops and other training methods utilized by the firm helps him a lot in updating his skills and knowledge to conform to modern trends in his field. Work usually ends at the official closing time (5pm) but he seldom finishes up latest by $6 \mathrm{pm}$. He works six days in a week with one day for rest. He has the liberty however to choose any

particular day he prefers to take as the resting day. He believes his work does not in any way affect his social obligations. Break time at work is an hour and can be taken whenever he feels free.

\subsubsection{Role conflict and ambiguity}

The job description clearly spells out his duties as the marketing manager. He knows exactly what to do and how to go about accomplishing each task. The monthly target of the firm is to reach out to not less than 200 corporate bodies within and outside of the region of which more than $50 \%$ are expected to patronage in the services of the hotel. He stated further that aside the hotel rooms, they also have facilities such as the main restaurant, local restaurant, and four bars of which they expect patronage from all these facilities. From the interview the marketing manager made it clear to us that they usually receive feedback from the corporate entities which they showcase their facility to, a feedback representing not less than their monthly target since there will be some query from top management if they hit below their monthly target. He sometimes performs functions which are not directly related to his job. 4.6.3 Resource inadequacy and working conditions
The service department of the hotel consists of 40 associates. Twenty of these associates are waiter and waitresses whilst five works as customer service representatives and the fifteen are supervisors and departmental heads. The manager believes he does not have enough workforces to manage the tasks of the department effectively. He emphasized associates sometimes work for more hours when the hotel have full house.

\subsubsection{Management style and monitoring}

The manager believes giving associates as much freedom to operate and occasionally providing them with direction is the best way to lead. He prefers to go round frequently to observe and give further directions when necessary. In his words he says, "I manage these young people filled with passion to serve with diligence and professionalism. My job is to manage this passion efficiently to achieve our collective goal". He provides feedback to associates constantly urging those performing poorly to seek help from the others or himself. From his cordial relationship, associates feel comfortable coming to him for help whenever they are challenged. He seldom helps with financial assistance.

\subsubsection{Job security}

The manager has a documented contract with the firm protected by labor laws of Ghana. From his years working with firm, he knows if he maintains his current streak of performance he may be up for promotion into middle or upper level management and refuted the idea of likelihood of losing his job.

\subsubsection{Job stress}

The manager mentioned there are some forms of stressors existing within their department due to the nature of their job and the satisfaction of people with varied backgrounds. His explanation can be directly related to the point of view of (Chenet et al., 1999) which states that "Job performance at the service encounter is directly correlated to service quality". The underlying assumption is that the customer's perception of a service encounter is a vital part of the service. For that reason, the actual service delivery is 
considered the moment of truth (Carlzon, 1987; Normann, 1983). It is at this point that the customer formulates the perception of quality, satisfaction, and long-term loyalty.

Unlike the commercial service sector where the product offering is a good or service, social marketers in social service organizations primary offering is a behavior change (Andreasen, 1995). Because of this uniqueness, quality is very difficult for the customer to assess.

He added that these challenges result in poor performance of his associates and some associates end up absenting themselves and not being punctual to work which eventually affects productivity and achievement of their targets. According to the marketing manager, setting of realistic goals, employing associates with passion for the job, emphasizing team performance etc. are some factors he believed relieved them of stress. He however mentioned the difficulty of associates' to understand some of the strategies for pitching services to be his most significant stressor. Such associates are usually employed with no practical experience in serving and tend to learn on the job. He has to spend more hours explaining and demonstrating the practicality of such strategies to them. He also has to be reachable always even during his resting day. He answers numerous calls from potential customers even after official working hours. He further noted inconsistency of sales within the month causes uneasiness. An example is when by the middle of the month sales has not reached half or in extreme cases one-third of target. In such instances the marketing team follows up on potential customers who have used their facility before and try as much as possible to showcase new packages by intensifying their marketing policies and promotions. Aside the usual discomforts with stress, he has not experienced any health related threats.

\section{DISCUSSION ON STRESS MANAGEMENT}

This study describes how workplace stress affects the health of service personnel at Kingstel Hotel and how performance and productivity of the organization is affected as well. I tried to analyze the causes of stress through the discussion with the marketing manager and also investigate how to manage workplace stress two different perspective which includes the individual point of view and from the organizational perspective.

\subsection{Causes of Job Stress}

Through the studies on Kingstel Hotel, the researcher find out that on-the-job stressors include lack of participation in decision-making, ineffective management style and unpleasant work environments that includes disruptive noise levels. In fact, nearly 60 percent of workers in one study reported that noise such as coworker conversations enhanced by open offices caused added distraction and stress, and a study at Cornell University showed that even lowlevel office noise increased stress hormone levels.

Longer working hours is another prime stressor. Almost half of employers report business performance is being affected by the stress of employees working long hours, and other impactful factors. Working overtime can result in poor mental performance, increased illness and workplace injuries.

The downturned economy and corresponding job layoffs, salary cuts, and heavier workloads have added to the stress in workers' personal lives, especially as they confront strained financial issues and compressed time allotment for family obligations.

"Stress flows both ways," explains Michael Baime, M.D., Clinical Associate Professor of Medicine at the University of Pennsylvania Health Advocate, Inc.

Pressure at the workplace is inevitable and can be seen as a natural feature of human life. However, stress beyond a particular level can lead to both psychological and physiological issues, which in turn 
can have a negative impact on the employee's performance in the organization (Kavitha, 2009). There are various sources of job stress, which are described below. The causes of work related stress come from both inside- and outside the organization.

\subsubsection{Individual approach}

With the discussion with Mr. Harry the marketing manager of Kingstel Hotel the researcher tried to find out how he manages stress personally where he responded that he loves to have fun. On his resting day, he makes time to relax and engage in activities he actually enjoys. He visits the gymnasium to keep his body in good shape, loves sauna, surfing and going to the club. On holidays he usually visits his parents or have his parents come over. He takes alcohol in minimal quantity and not frequently and stays off all other forms of drugs.

\subsubsection{Organizational approach}

From the organizational perspective, there are other organizational policies which can be implemented to help service personnel to cope with workplace stress but the more realistic ones includes flexibility at work and realistic targets. Also the marketing manager stated that he believes the organization does their best to make him and his associates comfortable. Moreover, there can be frequent training and exercises in addition to their knowledge, skills and expertise. The organization can also organize a lot of social events where associates will stand the chance to meets colleagues from other branches and departments to socialize. The organization can also show an appreciation by valuing performance and celebrating with them when targets are met. These and many other practices could be adopted by the organization which will help to manage workplace stress for the employees of the hotel.

Additionally, based on the discussion with the manger, his take as to how best to manage stress he described having a well laid plan, constant evaluation of performance, self-correction and efficient management of time as the ideal approach.

\subsection{Comparative Analysis of Stress Theories and} Practice

The interviewee understood clearly the concept of stress and how likely it can affect him and his associates in such a competitive market. Most of the theories of stress were pretty much the same in practice. This section brings to fore how the theories of job stress manifest itself at the workplace by comparing it to the findings of the interview.

Firstly, the interviewee recognized the essential role eustress plays in his department. He noted whenever there was fear of failing to meet their monthly targets, the staff body meets to decide on the best approach to overcome their dilemma. The uneasiness and sleepless nights actually pays off when almost every member of his team tries to make valuable contributions to the plan being developed to overcome the situation, he says. He however makes sure he keeps such zeal and energy under control to avoid the many negative effects that may arise when eustress finally turns into a distress.

\subsubsection{Demand-Control model}

As we have highlighted in the literature review, this theory states that job stress will be highest when job demands are high and control is low. From the analysis of the questionnaire, it could be clearly deduced that this theory actually exists within the firm to an extent. The Marketing Manager reported his most important stressor to be teaching associates without any prior marketing experience to appreciate their sales plan and strategy for meeting target. From this scenario, the concept of demand-control model can be interpreted as having the power to choose experienced staff with much needed sales skills to meet targets. The manager does not have control over the selection and hiring of the associates he's 
supposed to work with and therefore he ends up spending more than enough energy to train these associates. The manager however felt it was better the decision of firing and promoting people was someone else's responsibility. He felt firing someone is a big deal which end up stressing him out. He therefore preferred the current arrangement where he only makes recommendation for such actions.

\subsubsection{Management style}

Management style as described earlier affects the psychological climate of the workplace, and certain styles of dealing with subordinates create more stress than others. The manager almost all the time goes round with the subordinates to ensure that the service personnel are at their post and discharging their duties required of them. His presence was however not to intimidate his staff but rather observe their actions from afar and provide feedback on performance. He believed giving subordinates much space to operate and providing direction when necessary helped developed their sales skills.

The manager also maintained an open door policy by always being ready to help his subordinates whenever they came to him. He also resolved all conflicts that arose in his department quickly to avoid tensed atmosphere.

\subsubsection{Working conditions}

The manager believed it was the best place he would want to work. He maintained a good relationship with his subordinates and they in turn accorded him with maximum respect. He had a good relationship with other managers and his immediate boss. The flexibility which the job provided gave the manager freedom to choose his schedule. Choosing his own convenient time to go on break and have his resting day gave him the opportunity to get the most out of these free periods.

\subsubsection{Monitoring}

The manager felt independent going about his functions. Furnishing his superiors with useful information including progress reports of the hotel and employees' performance was very essential but aside these mandatory functions, he was virtually running his own crew his way. The most important concern of upper management was achieving his monthly target which he delivered perfectly and therefore enjoyed much autonomy. With this independence, most decisions to be made concerning his department were at his own discretion. He made these decisions with his subordinates instead who in turn will together with him implement these decisions.

The researcher also realized from the analysis of the questionnaires that service personnel work for more hours and have less time for rest and other personal stuffs. This is achievable by strict monitoring of associates. The manager made it clear that there are some existing rules such no usage of mobile phone during working hours and other activities which are not related to their jobs are discouraged. He stated further that his emphasis on rewarding team performance rather than on individual basis relieved him of a lot of potential job stress. Individual basis means keen monitoring of performance, unhealthy competition, unnecessary tension and barriers to communication among associates. Team performance encouraged sharing of ideas, lending each other a helping hand in times of need etc. which reduces the workload of the manager.

\subsubsection{Job security}

The manager's job to him was secured. The most important factor is for the company to be doing well and making profits. This will in turn form the solid basis of their security of tenure. He takes his duties 
seriously and believes when others do same there will be nothing to worry about.

\section{SOLUTIONS AND RECOMMANDATIONS}

This part of the paper presents recommendations and solutions that would help in managing workplace stress. It also suggests some managerial techniques which can effectively help in managing stress for employees in the service sector and hence increase productivity.

\subsection{Supportive Management and Personnel} Development Programs

One of the most important factors in the service industry is about the service which is being rendered by an organization, since customers relate the quality of service to the attitude, emotions and the personality of service personnel who render the service to them which eventually affects the company's public image. Therefore the researcher hereby recommends to management of Kingstel Hotel Limited to provide effective supportive and personal development opportunities for associates. There is also the need for management to encourage teamwork and team participation so as to lighten the workload of associate and hence minimize workplace stress. This can encompass anything from leadership training or building a new skill, to simply pursuing a passion that inspires an employee in and out of the workplace. Unfortunately, the issues of management support to employees is not one-size-fits, most management support and personal development plans fail because they are not driven by the employees' interests. Therefore, this study suggests to management to strictly assess the nature, benefits and implications of supportive programs in other to furnish service personnel with the right personal development initiatives, while still giving them the autonomy they need to grow in their own way.

6.2 Clearly define the role of each employee
The management of Kingstel Hotel need to clearly state to the new employees exactly what are their expectations and make sure to repeat them over and over as they orient and on-board them into their new job. The management also needs to have these honest discussions about expectations when the employee takes on a new role in the company, where they are moving up, down or sideways in the organizational structure. This recommendation was made due to the fact that the degree of perceived incongruence or incompatibility of organizational expectations associated with job performance may result in increased levels of job stress in the organization.

6.3 Involvement of associates in decision making

In an organization where employees are involved in decision making, it makes them feel safe and secured and are willing to give their best. This is not only helpful for the employees; it also helps management in understanding what the team members need and provides them with new ideas. When personal development and management support is part of the company culture, employees feel free to talk about their goals and needs with their supervisors, other superiors, and the rest of their team to develop solutions, within budget of course, that can benefit everyone.

It is also crucial in such an environment to build communities of practice or peer learning groups where people can share their experiences and find people with similar challenges who they can talk to. Another option is to support development and employee safety by encouraging people to learn through cross-pollination (i.e. go see what others are doing in the same field) in other areas of the company. Besides management support to employees, an effective communication can turn the workplace to a friendly environment where employees are comfortable and can focus on doing what they do best. To get there, managers need to devise a grounded communication approach that is equal parts clarity, empathy, and honesty. 


\subsection{Motivation and Needs of Employees}

The reality of employee' attitude is more related to the subjective factors of employee satisfaction. The overall satisfaction of employee also depends on some other objective measures worth to be taken into account.

6.4.1 Conscious effort motivation and satisfy the need of employees

In a way of drawing into attention the need and importance of motivating employees and striving to satisfy their needs, the researcher however introduce to the management of Kingstel Hotel the concept of Maslow's hierarchy of need which focuses on the "superior" motivations of man in his hierarchy as well as the foundations of psychic health. His hierarchy of needs means that man attains the full development of his psyche only if he is satisfied on all levels: physiology, security, love (belonging), esteem (recognition) and self- fulfillment (creativity). Moreover, this hierarchy is generally represented in the form of a pyramid that, from the bottom up, distinguishes five levels of need:

1. Basically, physiological needs (such as hunger, thirst);

2. The next one is the security and protection need (such as the desire for a roof or good insurance);

3 . Then comes the needs of belonging, social needs that reflect the desire to be part of a family, a group, a tribe;

4. That previous step is followed by the self-esteem needs (which allow one to look in the mirror in the morning);

5. Finally, appears at the top of the hierarchy, the need of self-fulfillment (which refers to the desire to realize oneself through a work, an engagement).

The pyramid which has been attributed to Maslow badly represents the richness of its analysis, and especially betrays the dynamic vision that it had needs in the construction of the personality.
Maslow believes that the basic needs (physiological and safety) are met, the person then seeks to satisfy other needs of higher order so as to constantly fuel the motivations. A

higher order need can only be satisfied if precedents are. Thus, to apply this model to the service personnel at Kingstel Hotel, the researcher does not emphasize on motivating employees in terms of esteem and accomplishment if threats of dismissal undermine security and if wages are not sufficient to satisfy fully the physiological needs.

Maslow once again holds an optimistic discourse in as much as he considers that it is possible for employees to be able in their work to fulfill themselves, provided that the management is participative (Douglas McGregor's theory).

Maslow offers a sociological study of spirituality in which he classifies with great fitness the various paroxysmal manifestations, such as revelation. His approach is that a scientist who globally approaches a dimension of religious fact in a macroscopic way, either as a sociologist or even as an ethnologist, and then uses a psychological analysis to address the microscopic scale of the paroxysmal experience

\section{Conclusion}

Through the questionnaires, a lot of interesting and important information was discovered concerning workplace stress management. The manager's responses clearly identified with the stress management theories. Stress management policies such as enough control to match job demands, job security, flexible work schedule, team performance over individual accomplishments, greater discretion on the part of associates, etc. will lead to minimum job stress in service industries. There is also the need for service personnel to develop a strong passion and love for rendering services which will result in intrinsic motivation and this will eventually grant them positive energy for the successful execution of 
duties. Kingstel Hotel is almost an ideal place where the work environment supposed to be stressful is managed well enough to produce better job performance whilst keeping stress to its minimum. The researcher also found out that some theoretical recommendations for reducing and combating stress are practiced in one way or another.

This research work offers a greater understanding of the complexity that job stress places not only on service personnel's job performance but also on their desire to switch positions within the organization or to leave the organization. By taking a global look at the antecedents and consequences of job stress from the service personnel's perspective, it is the researcher's belief that the study provides a clearer picture of the job stress process for service personnel. Findings of the study show that there are at least five constructs that impact job stress (i.e., role ambiguity, role conflict, role overload, the attitude of uncooperative colleagues, and emotional labor), but it is also evident that other sources of job stress exist that still need to be investigated. Finally, it is also known that job autonomy reduces job stress, but not job stress coming from perceived customer demands.

Moreover, there is an indication from the analysis that, the more uncooperative colleagues tend to be in an organization, the heavier workload will be. Also, teamwork and its effectiveness have more impact in reducing job stress coming from the five sources of job stress on the five outcome constructs (i.e., attitude toward the job, working environment, overall organizational commitment, overall job satisfaction, and attitude of team members) which were examined in this study. It is also apparent that the influence team members' uncooperative attitudes and the volume of workload and performance are correlated. It is hoped that the findings of this research endeavor will create interest among other researchers to study this important research subject. It is believed that understanding coming from this research is relevant for both managers and employees in the service industry such as hotel management, banking institutions, and telecommunication companies. More research is needed to measure the impact of stress on the health of employees and how it affect labor turnup in an organization. Stress management training is being provided to the employees, even then there is need for more empirical research in this field. There is need to apply all stress related theories and frameworks into practice.

\section{ACK NOWLEDGEMENTS}

My utmost appreciation goes to Dr. Felix K. Semavor, the Chairman of Kings University College and the entire management and staff for the financial support throughout my two and half years of post-graduate studies.

I would like to specially thank my supervisor Professor Huiying Chen for her constant effort to guide, motivate and advise me on how to go about this research work. I see her as not only my supervisor but a teacher and a mentor. She has really taught me in these few days how to work faster, harder and also accept and respect the views of others. I also want to thank all of my teachers who have impacted both academic and social knowledge on me during these years of studies at Liaoning University. I am so much grateful to my teacher Professor Li Bin and all professors of Liaoning University Business School, and all teachers of the Institute of International Education of Liaoning University who have been supportive to me in conducting this research work. Not forgetting the professors who provided me extensive personal, psychological and professional guidance and taught me a great deal of insight in both academic research works.

I am grateful to all colleagues and friends with whom I have had the pleasure to work during my postgraduate studies.

My sincere appreciation goes to my Pastors Jonas B. Beddim and family, George Ackah-Watson and 
family, Benjamin Otoo and family, Ahmed Anane Acheampong and family, and my beloved friends Elizabeth Naa Akushia Antie, Lu Xing, Ebenezer Yaw Ofosuhene and the entire family of Pensa Shenyang for their support in diverse ways, may the good Lord bless you in all your accomplishments.

Not forgetting of my parents Mr. and Mrs. Acquah and the entire Acquah family for their unflinching support, love and care towards my education. The family in china here has shown me usual kindness and I really appreciate the love and care.

\section{DEDICATION}

To my dear parents and the entire Acquah family who have solidly stood by me in terms of finance and affection throughout my undergraduate studies till now. I also specially dedicate this research work to all my friends and loved ones who have supported me in diverse ways.

\section{REFERENCES}

[1]. Abbott, A. 2001. Chaos of Disciplines. United Kingdom.

[2]. Agrawal, R. 2001. Stress in life and at work, Response Books London.

[3]. Aiello, J. R., \& Kolb, K.J. (1995) Electronic performance monitoring and social context: Impact on productivity and stress. Journal of applied psychology, 80:339-353

[4]. Athanassopoulos, A. D. (2000, March). Customer Satisfaction Cues to Support Market Segmentation and Explain Switching Behavior. Journal of Business Research, 47, 191-207.

[5]. Andreasen, A. R. (1995). Marketing Social Change. San Francisco, CA: Jossey-Bass.

[6]. Barnes, B (January 2003) the new face of air rage. Wall Street Journal (Eastern Edition).

[7]. Weekend Journal: W1

[8]. Bickford, M. (2005). Stress in the Workplace: A General Overview of the Causes, the Effects, and the Solutions. Canadian Mental Health
Association Newfoundland and Labrador Division, 1-3.

[9]. Bowen, D. E. \& Schneider, B. (1985). Boundary-Spanning Role Employees and the Service Encounter: Some Guidelines for Management and Research. In J. Czepiel, M. Solomon, \& C. Supernant (Eds.), The Service Encounter: Managing Employee/Customer Interaction in Service Businesses (pp. 127-148). Lexington, MA: Lexington Books.

[10]. Burnham, T. A., Frels, J. R., \& Mahajan, V. (2003, Spring). Consumer Switching Costs: A Typology, Antecedents, and Consequences. Journal of Academy of Marketing Science, 31, 109-126.

[11]. Carlzon, J. (1987). Moments of Truth. Cambridge, MA: Ballinger Publishing Company.

[12]. Canadian Union of Public Employees. (2003). Enough Workplace Stress: Organizing for Change.

[13]. Cano, C., Carrillat, F., \& Jaramillo, F. (2004, June). A Meta-Analysis of the Market Orientation-Business Performance Relationship: Evidence from Five Continents. International Journal of Research in Marketing, 21, 179-200.

[14]. Chenet, P., Tynan, C., \& Money, A. (1999, October). Service Performance Gap: ReEvaluation and Redevelopment. Journal of Business Research, 46, 133-147.

[15]. Chenet, P., Tynan, C., \& Money, A. (1999, October). Service Performance Gap: ReEvaluation and Redevelopment. Journal of Business Research, 46, 133-147.

[16]. Fletcher, B.C. (1994).The epidemiology of occupational stress. In: C.L. Cooper and R. Payne (Eds). Causes, Coping and Consequences of Stress at Work. Wiley \& Sons, Chichester.

[17]. Folkes, V. S. \& Patrick, V. M. (2003, June). The Positive Effect in Perception of Service: 
Seen One, Seen Them All?" Journal of Consumer Research. 30, 125137.

[18]. Goolsby, J. R. (1992, Spring). A Theory of Role Stress in Boundary Spanning Positions of Marketing Organizations. Journal of Academy of Marketing Science, 2, 155164.

[19]. Hecker, D. E. (2001, November). Occupational Employment Projections to 2010. Monthly Labor Review, 57-84.

[20]. Holton, C. J. (1983) Machiavellianism and managerial work attitudes and perceptions,

[21]. Psychological Reports, 53:432-434

[22]. Jackson, S. E., \& Schuler, R. 19995. A mentalanalysis and occupational critique of research on role ambiguity and role conflict in work settings. Organizational Behavior and Human Decision Process, 36: 16-78

[23]. Jamal, M. (1984) Job stress and job performance controversy: An empirical assessment.

[24]. Organizational Behavior and Human Performance. 33:1-21.

[25]. Kahn, R. L., Wolf, D. M., Quinn, R. P., Snock, J. D., \& Rosenthal, R. A. (1964). Organizational Stress: Studies in Role Conflict and Ambiguity. New York, NY: Wiley.

[26]. Karasek, R. 1979. Job demands, job decision latitude, and mental strain: Implications for job redesign. Administrative Science Quarterly, 24:285-306; Karasek, R. 1989. Control in the workplace and its health related aspects. In S.L. Sauter, J.J. Hurrell, \& C. 1. Cooper (Eds.), Job control and worker health. New York: John Wiley \& Sons, pp. 129-159.

[27]. Kawakami, N., \& Haratani, T. (1999). Epidemiology of job stress and health in Japan: review of current evidence and future direction. Industrial health, 37(2), 174-186.

[28]. Kavitha, G. 2009. Occupational Stress and Coping Strategies, Discovery Publishing House Pvt. Limited
[29]. Kotler, P., Roberto, N., \& Lee, N. (2002). Social Marketing: Improving the Quality of Life. Thousand Oaks, CA: Sage Publications.

[30]. Managing stress at work: Discussion document, United Kingdom Health and Safety Commission, London, 1999.

[31]. Mark, G. M. (2008). The relationship between workplace stress, and job characteristics, individual differences, and mental health. $\mathrm{PhD}$ Thesis, Cardiff University.

[32]. McAlexander, J. H., Kaldenberg, D. O., \& Koenig, H. F. (1994, Fall). Service Quality Measurement. Journal of Health Care Marketing, 14, 34-40.

[33]. Michael A. Hitt, C. Chet Miller, Adrienne Colella. Organizational Behavior: a Strategic Approach. 2006

[34]. Normann, R. (1983). Service Management: Strategy and Leadership in Service Businesses. New York, NY: John Wiley and Sons.

[35]. Salovey, P. \& Mayer, J. D. (1990). Emotional Intelligence. Imagination, Cognition and Personality, 9, 185-211.

[36]. Shaw, J. B., \& Weekly, J. A (1985). The effects of objective work-load variations of psychological strain and post-work-load performance. Journal Management, 11:87-98; Ganster \& Schaubroeck, work stress and employee health.

[37]. Shostack, G. L. (1977, April). Breaking Free From Product Marketing. Journal of Marketing, 41, 73-80.

[38]. Singh, J., Goolsby, J. R., \& Rhoads, G. K. (1994, November). Behavioral and Psychological Consequences of Boundary Spanning Burnout for Customer Service Representatives. Journal of Marketing Research, 31, 558-569.

[39]. United States National Institute of Occupational Safety and Health, Cincinnati, 1999 BMC Public Health 2006

[40]. Wang, G. \& Netemeyer, R. G. (2002). The Effects of Job Autonomy, Customer 
Demandingness, and Trait Competitiveness on Salesperson Learning, SelfEfficacy, and Performance. Journal of the Academy of Marketing Science, 30, 217-228.

[41]. WORLD Health Organization 2017, Informed consent for Qualitative studies World Health Organization.

[42]. www.vichealth.vic.gov.au/workplacestress (accessed September 28, 2019)

[43]. http://www.economiesafricaines.com/en/countr ies/ghana/economic-sectors/the-service-

[44]. sector (accessed November 4, 2019)

Item-Total Statistics

\begin{tabular}{|c|c|c|c|c|c|}
\hline & $\begin{array}{c}\text { Scale } \\
\text { Meanif } \\
\text { Item } \\
\text { Delete } \\
\text { d }\end{array}$ & $\begin{array}{c}\text { Scal } \\
\mathbf{e} \\
\text { Vari } \\
\text { ance } \\
\text { if } \\
\text { Item } \\
\text { Deleted }\end{array}$ & 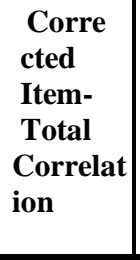 & $\begin{array}{c}\text { Squared } \\
\text { Multiple } \\
\text { Correlat } \\
\text { ion }\end{array}$ & $\begin{array}{c}\text { Cronbach's } \\
\text { Alpha if } \\
\text { Item } \\
\text { Dele } \\
\text { ted }\end{array}$ \\
\hline VAR00001 & 111.0545 & 195.386 & .333 & .823 & .697 \\
\hline VAR00002 & 111.0364 & 198.184 & .305 & .800 & .700 \\
\hline VAR00003 & 111.1455 & 208.608 & .006 & .631 & .716 \\
\hline VAR00004 & 110.8727 & 198.965 & .241 & .855 & .703 \\
\hline VAR00005 & 111.0364 & 196.962 & .331 & .743 & .698 \\
\hline VAR00006 & 111.0182 & 211.870 & -.082 & .739 & .721 \\
\hline VAR00007 & 111.3455 & 196.527 & .350 & .741 & .697 \\
\hline VAR00008 & 111.2364 & 203.591 & .134 & .705 & .710 \\
\hline VAR00009 & 110.9273 & 199.439 & .271 & .880 & .702 \\
\hline VAR00010 & 111.2364 & 198.628 & .287 & .829 & .701 \\
\hline VAR00011 & 110.9636 & 195.591 & .354 & .857 & .696 \\
\hline VAR00012 & 111.3091 & 195.773 & .409 & .768 & .695 \\
\hline VAR00013 & 111.0727 & 203.735 & .140 & .861 & .709 \\
\hline VAR00014 & 111.1455 & 191.608 & .516 & .846 & .688 \\
\hline VAR00015 & 111.1455 & 206.090 & .085 & .725 & .712 \\
\hline VAR00016 & 111.0545 & 204.867 & .133 & .921 & .709 \\
\hline VAR00017 & 111.1273 & 206.891 & .050 & .769 & .714 \\
\hline VAR00018 & 111.1636 & 206.584 & .070 & .647 & .712 \\
\hline VAR00019 & 111.2000 & 198.570 & .266 & .634 & .702 \\
\hline
\end{tabular}

\begin{tabular}{|c|c|c|c|c|}
\hline VAR00020 & 111.2727 & | 201.276 & .238 & .821 \\
\hline VAR00021 & 111.3818 & \begin{tabular}{|l|}
204.648 \\
\end{tabular} & .119 & .863 \\
\hline VAR00022 & 110.9455 & 209.534 & -.020 & .782 \\
\hline VAR00023 & 111.1818 & $|215.670|$ & -.176 & .689 \\
\hline VAR00024 & 110.9636 & 197.036 & .305 & .756 \\
\hline VAR00025 & 110.8364 & 200.362 & .259 & .870 \\
\hline VAR00026 & 111.2545 & $\mid 196.045$ & .390 & .728 \\
\hline VAR00027 & 111.2545 & 216.230 & -.189 & .657 \\
\hline VAR00028 & 110.9273 & $\mid 184.698$ & .691 & .878 \\
\hline VAR00029 & 110.8364 & 201.213 & .225 & .773 \\
\hline VAR00030 & 111.2909 & 195.655 & .435 & .596 \\
\hline VAR00031 & 111.2727 & \begin{tabular}{|l|}
199.572 \\
\end{tabular} & .272 & .871 \\
\hline VAR00032 & 111.3636 & 212.828 & -.108 & .675 \\
\hline
\end{tabular}

Cite this article as :

Alex Acquah, Prof. Huiying Chen, "The Impact of Workplace Stress Management in a Business Organisation in the Service Industries - A Case Study on Kingstel Hotel Limited -Takoradi, Ghana ", International Journal of Scientific Research in Science, Engineering and Technology (IJSRSET), Online ISSN : 2394-4099, Print ISSN : 2395-1990, Volume 8 Issue 3, pp. 240-275, May-June 2021. Available at doi : https://doi.org/10.32628/IJSRSET218342 Journal URL : https://ijsrset.com/IJSRSET218342 